University of Wollongong

Research Online

Faculty of Engineering and Information

Faculty of Engineering and Information

Sciences - Papers: Part B

Sciences

2018

Development of a new Geant4-DNA electron elastic scattering model for liquid-phase water using the ELSEPA code

\author{
W Shin \\ Yonsei University \\ M Bordage \\ Universite Paul Sabatier \\ Dimitris Emfietzoglou \\ University of loannina \\ Ioanna Kyriakou \\ University of loannina \\ Dosatsu Sakata \\ University of Wollongong, dousatsu@uow.edu.au
}

See next page for additional authors

Follow this and additional works at: https://ro.uow.edu.au/eispapers1

Part of the Engineering Commons, and the Science and Technology Studies Commons

Research Online is the open access institutional repository for the University of Wollongong. For further information contact the UOW Library: research-pubs@uow.edu.au 


\title{
Development of a new Geant4-DNA electron elastic scattering model for liquid- phase water using the ELSEPA code
}

\author{
Abstract \\ This paper presents the calculation of new elastic scattering cross sections for the simulation of electron \\ interactions in liquid water. The calculations are based on the "ELastic Scattering of Electrons and \\ Positrons by neutral Atoms" code, which adopts a Dirac partial wave analysis. A Muffin-tin potential was \\ used in order to account for the liquid-phase of water, and the optical parameters of the correlation- \\ polarization and the inelastic absorption potentials were optimized against vapour-phase water data. The \\ differential and total elastic scattering cross sections calculated in the present work show a global \\ agreement with the experimental data. The impact of these elastic scattering cross sections on the \\ transport of electrons in liquid water was evaluated by track-structure simulations of range, dose-point- \\ kernel, microdosimetric spectra, and ionization clustering using the Geant4-DNA simulation toolkit. The \\ results are compared against those obtained with the elastic scattering models already available in \\ Geant4-DNA and are discussed.

\section{Disciplines} \\ Engineering | Science and Technology Studies

\section{Publication Details} \\ Shin, W. G., Bordage, M. C., Emfietzoglou, D., Kyriakou, I., Sakata, D., Min, C. H., Lee, S. B., Guatelli, S. \& \\ Incerti, S. (2018). Development of a new Geant4-DNA electron elastic scattering model for liquid-phase \\ water using the ELSEPA code. Journal of Applied Physics, 124 (22), 224901-1-224901-15.

\section{Authors} \\ W Shin, M Bordage, Dimitris Emfietzoglou, loanna Kyriakou, Dosatsu Sakata, C Min, Sang Bae Lee, \\ Susanna Guatelli, and Sebastien Incerti
}




\title{
Development of a new Geant4-DNA electron elastic scattering model for liquid-phase water using the ELSEPA code
}

\author{
W.-G. Shin, ${ }^{1,2,3, a)}$ M.-C. Bordage ${ }^{4,5}$ D. Emfietzoglou, ${ }^{6}$ I. Kyriakou, ${ }^{6}$ D. Sakata, ${ }^{7}$ C. H. Min, ${ }^{3}$ \\ S. B. Lee, ${ }^{8}$ S. Guatelli, ${ }^{7}$ and S. Incerti ${ }^{1,2, b)}$ \\ ${ }^{1}$ UMR 5797, Bordeaux University, F-33170 Gradignan, France \\ ${ }^{2}$ UMR 5797, CENBG, IN2P3, CNRS, F-33170 Gradignan, France \\ ${ }^{3}$ Department of Radiation Convergence Engineering, Yonsei University, Wonju, South Korea \\ ${ }^{4}$ UMR 1037 CRCT, Université Toulouse III-Paul Sabatier, Toulouse, France \\ ${ }^{5}$ UMR 1037 Inserm, Toulouse, France \\ ${ }^{6}$ Medical Physics Laboratory, University of Ioannina Medical School, 45110 Ioannina, Greece \\ ${ }^{7}$ Centre for Medical Radiation Physics, University of Wollongong, Wollongong, New South Wales, Australia \\ ${ }^{8}$ Proton Therapy Center, National Cancer Center, Goyang, South Korea
}

(Received 9 July 2018; accepted 18 November 2018; published online 13 December 2018)

This paper presents the calculation of new elastic scattering cross sections for the simulation of electron interactions in liquid water. The calculations are based on the "ELastic Scattering of Electrons and Positrons by neutral Atoms" code, which adopts a Dirac partial wave analysis. A Muffin-tin potential was used in order to account for the liquid-phase of water, and the optical parameters of the correlation-polarization and the inelastic absorption potentials were optimized against vapour-phase water data. The differential and total elastic scattering cross sections calculated in the present work show a global agreement with the experimental data. The impact of these elastic scattering cross sections on the transport of electrons in liquid water was evaluated by track-structure simulations of range, dose-point-kernel, microdosimetric spectra, and ionization clustering using the Geant4-DNA simulation toolkit. The results are compared against those obtained with the elastic scattering models already available in Geant4-DNA and are discussed. Published by AIP Publishing. https://doi.org/10.1063/1.5047751

\section{INTRODUCTION}

In order to investigate the induction of biological damage from ionizing radiation at the sub-cellular scale, track structure simulation codes using Monte Carlo methods (MCTS) have been under development for several decades. ${ }^{1-12}$ These codes usually approximate the biological medium as liquidphase water, the main component of biological tissues. Since most physical damages are caused by secondary electrons, many sets of electron cross section models for liquid water have been proposed so far. ${ }^{13-18}$ In particular, it was reported that the interactions of low energy electrons (kinetic energy $<100 \mathrm{eV}$ ) should be carefully modeled in order to evaluate the damage to the DNA molecule, which is induced mainly through ionizations. ${ }^{19}$ At such low energy, elastic scattering also plays a key role; indeed, even if this process is not associated with significant energy loss, it contributes to the spatial distribution of electrons in the irradiated medium. ${ }^{20}$

In brief, in order to accurately calculate the elastic scattering cross section of electrons in liquid water, three main approaches have been proposed: the Born collision model, ${ }^{21}$ the non-relativistic (Schrödinger) partial wave model, and the relativistic (Dirac) partial wave analysis. ${ }^{22}$ The Dirac partial wave method is currently the most advanced to calculate such cross sections. Unfortunately, the validation of many of

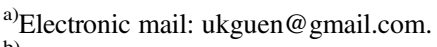

${ }^{\text {b) }}$ E-mail: incerti@ cenbg.in2p3.fr. Tel.: +33 5571208 00. Fax: +33 55712 0801.
}

these calculations is difficult due to the scarcity of reliable experimental data in the liquid-phase of water. ${ }^{23,24}$ However, at least for an incident energy above $60 \mathrm{eV}$, the calculated differential cross sections (DCSs) in liquid and vapour water show a similar trend as a function of scattering angle, with discrepancies up to about $67 \%$ at $0^{\circ} .{ }^{25}$ For this reason, the plausibility of calculated DCSs for the liquid-phase water is usually validated by comparison with theoretical models and experimental data in the vapour-phase of water.

In order to provide a track structure (TS) simulation toolkit freely accessible to the community, we extended during the last few years the general purpose Geant4 simulation toolkit in the framework of the Geant4-DNA project. ${ }^{4,24,26,27}$ Geant4-DNA is able to simulate step-by-step the interactions of electrons, hydrogen, and helium atoms, and their respective charge states down to a few eV (for electrons). Physical interactions such as elastic scattering, electronic excitation, ionization, and charge exchange are modeled, as extensively described in our previous publications. ${ }^{4,24,26,27}$ The default model proposed by Geant4-DNA to describe elastic scattering of electrons in liquid water is based on a partial wave approach, developed by Champion et al. ${ }^{14}$ This model presents some limitations, such as the lack of relativistic correction, a limited energy range, and disagreement of DCSs with the experimental data at low energy and intermediate angle.

In order to improve the accuracy of electron elastic scattering in Geant4-DNA, we propose to calculate the corresponding cross sections (total and differential) using the "ELastic Scattering of Electrons and Positrons by neutral Atoms" 
(ELSEPA) code developed by Salvat et al. ${ }^{28}$ This code uses the Dirac partial wave approach including relativistic corrections to calculate the electron elastic scattering cross sections. In this work, we use a new version of ELSEPA that was kindly provided by its authors. ${ }^{29}$ The advantages of ELSEPA are that one can easily change calculation parameters and interaction potential models, and it is possible to calculate DCSs from a few $\mathrm{eV}$ up to $1 \mathrm{GeV}$ in a variety of materials.

In Sec. II, we present the calculation of the elastic scattering cross sections using ELSEPA with the Muffin-tin approximation, which is typically employed to predict cross sections in the solid-phase material. ${ }^{30}$ Moreover, we describe the optical parameters included in the correlation-polarization and in the absorption potentials. The elastic scattering models already available in Geant4-DNA are briefly introduced as well as several Geant4-DNA applications that have been used in this work to evaluate the impact of the new model on TS simulations.

In Sec. III, we first describe the optimization of the correlation-polarization and absorption potentials optical parameters. The cross sections are then compared to the experimental data and to the other Geant4-DNA elastic models. Finally, their influence on TS simulations [range, dose point kernel (DPK), microdosimetry distributions, and clustering of energy deposition] is compared to simulations where the existing Geant4-DNA elastic models are used.

\section{MATERIALS AND METHODS}

\section{A. ELSEPA calculations}

In order to accurately calculate electron interaction cross sections in matter, one first needs to describe the interaction potential. Following ICRU Report $77,{ }^{31}$ we first consider the Fermi nucleus distribution (F), the Dirac-Fock electron distribution (DF), the Furness-McCarthy exchange potential (FM), the correlation-polarization potential with the local density approximation (LDA), and the LDA absorption potential (A), a combination denoted as (F-DF-FM-LDA-A), available in ELSEPA, and described in detail in Ref. 28.

In addition, the Muffin-tin approximation used for solid-phase materials was employed to predict the cross sections in the liquid-phase of water. The "Independent Atom Approximation" (IAA) was employed to coherently sum the projectile waves scattered by the individual atoms of the molecule. ${ }^{32,33}$ The IAA used in combination with the Muffin-tin model gives DCS values in better agreement with data than the alternative simpler additivity approximation (incoherent summation).

Moreover, it is well-known that the electrostatic and exchange potentials agree well with the experimental data in the high energy range (above the electron energy of $5 \mathrm{keV}$ ). However, the accuracy of the static field and static exchange approximations become gradually worse below this energy. ${ }^{34}$ To correct such disagreement, the optical model including correlation-polarization and absorption potentials was proposed. ELSEPA provides the best empirical parameters for the optical model. These optical parameters are basically phenomenological and were validated with noble gases.
Thus, for this work, it was also necessary to optimize these optical parameters for water, as we will describe later.

Finally, the DCSs calculated using the ICRU 77 "F-DF-FM-LDA-A" combination will be shown to compare our results with ICRU 77 recommendations. ${ }^{31}$

\section{Phase influence}

ELSEPA provides potential models in the free atom approximation for the vapour-phase and the Muffin-tin approximation for applications to the solid-phase. ${ }^{30,35}$ In contrast to the free atom approximation, the Muffin-tin potential assumes that the $\mathrm{Z}$ electrons of the neutral atom are confined within a sphere of a certain radius $R_{m t}$ centered on the nucleus to approximate solid-state, as explained by Salvat et al..$^{28}$

$$
V_{m t}(r)=\left\{\begin{array}{cc}
V_{s t, m t}(r)+V_{e x}(r)+V_{c p}(r)-i W_{a b s}(r), & r \leq R_{m t}, \\
V_{s t, m t}\left(R_{m t}\right)+V_{e x}\left(R_{m t}\right)+V_{c p}(r), & r>R_{m t},
\end{array}\right.
$$

$$
V_{s t, m t}(r)=V_{s t}(r)+V_{s t}\left(2 R_{m t}-r\right),
$$

where $V_{m t}(r)$ is the Muffin-tin potential, $V_{s t}(r)$ and $V_{s t, m t}(r)$ are the electrostatic interaction potential without and with Muffin-tin approximation, respectively. $V_{e x}(r)$ is the exchange potential, $V_{c p}(r)$ is the correlation-polarization potential, and $i W_{a b s}(r)$ is the imaginary absorption potential. It must be noted that the Muffin-tin approximation assumes a vanishing of the electron density $\rho_{e, m t}(r)$ outside the Muffin-tin sphere because it is valid for the solid-phase material which lacks free electrons: ${ }^{28}$

$$
\rho_{e, m t}(r)=\left\{\begin{array}{cc}
\rho_{e}(r)+\rho_{e}\left(2 R_{m t}-r\right)+\rho_{u}, & r<R_{m t}, \\
0, & r>R_{m t},
\end{array}\right.
$$

where $\rho_{u}$ is a constant normalizing the number of electrons to the atomic number.

In this work, we propose to use the Muffin-tin potential to mimic the liquid-phase of water. We choose the radius of the Muffin-tin model equal to $1.405 \AA$, which corresponds to half the average distance between oxygen atoms in liquid water. $^{36}$ This distance is larger than the length of the $\mathrm{O}-\mathrm{H}$ bond (equal to $0.991 \AA)^{37}$ because, in this work, we hypothesized that there are sufficient weakly-bound solvated electrons in the irradiated liquid water medium outside the water molecule (with typical binding energies of a few eV). ${ }^{38}$ This hypothesis resulted in a significant agreement with reference data on vapour-phase and in expected differences between vapour and liquid-phase.

\section{Correlation-polarization potential}

It is known that the correlation-polarization potential has an influence on the DCSs at small angles, and this effect is larger when decreasing the electron energy below $500 \mathrm{eV}^{34}$ ELSEPA provides a global correlation-polarization potential as a combination of two potentials: the Buckingham potential for long-range trajectories, based on a phenomenological formula deriving from a measured polarizability of the atom, ${ }^{39}$ and the "Local Density Approximation" (LDA) 
correlation potential. ${ }^{28}$ Alternatively, in another version of ELSEPA, the potential model for long-range trajectories can be calculated from Lindhard's high-energy formula ${ }^{40}$ with a static polarizability of $1.457 \AA^{3}$ proposed by the ICRU 77 report. ${ }^{31}$ Thus, we evaluated the influence of both potentials on the DCS. In addition, in the case of the Buckingham potential, we have the possibility to modify the adjustable energy-dependent parameter $b_{p o l}$ appearing in the expression of the potential cutoff parameter (preventing from divergence at zero radii). This parameter is proposed by default for noble gases and mercury ${ }^{28}$ as

$$
b_{p o l}^{2}=\max [(E-50 \mathrm{eV}) /(16 \mathrm{eV}), 1] .
$$

It is reported that $b_{p o l}$ primarily affects small scattering angles. ${ }^{34}$ The DCSs at small angles are the largest when $b_{\text {pol }}$ is equal to 1 , and they decrease when increasing $b_{p o l}$ above 1. However, the default expression of $b_{p o l}$ is too low to accurately calculate the DCSs for liquid water. Therefore, we examined the effects of $b_{p o l}$ on the DCSs, and we proposed an optimal expression for $b_{p o l}$ as a function of the incident energy $E$ based on the experimental data in the vapour-phase at zero or small scattering angles.

\section{Inelastic absorption potential}

In order to consider the energy loss associated with the inelastic scattering, the inelastic absorption potential must contain a negative imaginary part in Eq. (1), which mainly has an influence at intermediate and large scattering angles. In ELSEPA, there are two empirical parameters: the energy gap $\Delta$ and the absorption strength $A_{a b s}$.

The energy gap $\Delta$ is the minimum energy at which the energy loss by inelastic scattering starts. We used $8.22 \mathrm{eV}$ which is the threshold of the first excitation level in the Geant4-DNA Emfietzoglou model. ${ }^{41}$

The absorption strength $A_{a b s}$ of the inelastic absorption potential is suggested by Salvat et al., as "OP-I" $(2.00)^{34}$ or "OP-II" $(0.75){ }^{29}$ These values have been validated by comparison with experiments in noble gases. However, these phenomenological values are neither suitable for liquid nor vapour water. In this study, we calculated the DCSs according to the inelastic absorption potential, and we determined the optimal absorption strength $A_{a b s}$ which leads to the closest agreement with the experimental data in vapour water, based on discrete root-mean-square error (RMSE) between the experimental data and calculated DCSs.

\section{B. Other cross section models available in Geant4-DNA and experimental data}

Geant4-DNA proposes the so-called "physics constructors" which gather a list of particles and associated physical processes that must be taken into account for the simulation of transport in liquid water. Table I lists the different models used for the simulation of electron interactions in the three recommended Geant4-DNA physics constructors. ${ }^{26}$ For the validation of the calculated cross sections, we compared not only DCSs but also total elastic cross section (TECS) and momentum transfer cross section (MTCS) against elastic cross sections currently available in Geant4-DNA for simulations in liquid water, such as the Champion model and the CPA-100 model which both use partial wave analysis, ${ }^{14,15,42}$ and the screened Rutherford model (SR) and the Uehara screened Rutherford model (USR), which use the Born collision approximation. ${ }^{43,44}$

In addition, sets of experimental data in the gaseous phase of water presented in Hilgner and Kessler, ${ }^{45}$ Danjo and Nishimura, ${ }^{46}$ Katase et al. ${ }^{47}$ Sueoka et al. ${ }^{48}$ Shyn and Cho, ${ }^{49}$ Saglam and Aktekin, ${ }^{50}$ Johnstone and Newell, ${ }^{51}$ Shyn and Grafe, ${ }^{52}$ Cho et al. ${ }^{53}$ and Khakoo et al. ${ }^{54}$ are used for comparisons with the calculated cross sections.

The experimental data of Michaud et al. ${ }^{55}$ giving the elastic cross section in the solid phase of water are also compared with the calculated cross sections.

\section{Geant4-DNA examples for TS simulations}

Geant4-DNA proposes a set of example applications for the simulation of TS in liquid water. ${ }^{24}$ We used these examples in order to investigate the influence of the new elastic model on various electron track-structure characteristics. The simulations were performed with the existing Geant4-DNA physics constructors listed in Table I, and with these same constructors in which the elastic model has been replaced by the newly implemented model calculated with ELSEPA. The energy limits of "option 2," "option 4," and "option 6" constructors are determined by considering the energy limits of all processes (elastic, excitation, ionization): $10 \mathrm{eV}-1 \mathrm{MeV}, 10 \mathrm{eV}-10 \mathrm{keV}$, and $11 \mathrm{eV}-256 \mathrm{keV}$, for "option 2,"

TABLE I. Elastic and inelastic models employed in Geant4-DNA physics constructors and energy limits of applicability.

\begin{tabular}{|c|c|c|c|}
\hline \multirow[b]{2}{*}{ Geant4-DNA physics constructor ${ }^{26}$} & \multirow[b]{2}{*}{ Elastic } & \multicolumn{2}{|c|}{ Inelastic } \\
\hline & & Excitation & Ionization \\
\hline G4EmDNAPhysics_option $2^{\mathrm{a}}$ & $\begin{array}{l}\text { Champion model }(7.4 \mathrm{eV}-1 \mathrm{MeV})^{14} \\
\text { Screened Rutherford } \operatorname{model}^{\mathrm{b}}(9 \mathrm{eV}-10 \mathrm{keV})\end{array}$ & $\begin{array}{l}\text { Emfietzoglou dielectric model } \\
(9 \mathrm{eV}-1 \mathrm{MeV})\end{array}$ & $\begin{array}{l}\text { Emfietzoglou dielectric model } \\
(11 \mathrm{eV}-1 \mathrm{MeV})\end{array}$ \\
\hline G4EmDNAPhysics_option4 ${ }^{\mathrm{a}}$ & $\begin{array}{l}\text { Uehara screened Rutherford model } \\
(9 \mathrm{eV}-10 \mathrm{keV})^{44}\end{array}$ & $\begin{array}{l}\text { Emfietzoglou-Kyriakou } \\
\text { dielectric model }(8 \mathrm{eV}-10 \mathrm{keV})\end{array}$ & $\begin{array}{l}\text { Emfietzoglou-Kyriakou } \\
\text { dielectric model }(10 \mathrm{eV}-10 \mathrm{keV})\end{array}$ \\
\hline G4EmDNAPhysics_option6 ${ }^{\mathrm{a}}$ & CPA-100 (11 eV-256 keV) & CPA-100 (11 eV-256 keV) & CPA-100 (11 eV-256 keV) \\
\hline
\end{tabular}

aAbbreviated later as "option 2," "option 4," and "option 6" (or "default options"). The physics constructors including the ELSEPA elastic model are defined in this work as "option 2 ELSEPA," "option 4 ELSEPA," and "option 6 ELSEPA" (or "ELSEPA options").

bAlternative models of "option 2." The Champion model is used by default in Geant4-DNA. 
"option 4," and "option 6," respectively. Table II lists the Geant4-DNA examples used in this study. The processes of vibrational excitation and dissociative attachment were adopted for "option 2," except in the case of the "microyz" example for comparison with previously published works. ${ }^{56,57}$ The number of incident electrons was set to $10^{6}$ to obtain statistically meaningful results.

Regarding the simulations of track length and penetration ("range" Geant4-DNA example), we indicate in Table III the list of previously published works used to verify our simulations.

\section{RESULTS AND DISCUSSIONS}

\section{A. Determination of optimal options and parameters}

\section{Long-range correlation-polarization potential}

Figure 1 shows the effect of the long-range correlationpolarization potentials. The DCSs obtained with the Lindhard model for the correlation-polarization potential are much higher than the DCSs obtained with the Buckingham model and experiments, especially at $0^{\circ}$, up to $61 \%$ at $500 \mathrm{eV}$. This tendency of the Lindhard model does not agree with the general expectation that the DCSs of liquid-phase water are smaller than the DCSs of vapour-phase water at a small scattering angle. Accordingly, we decided to adopt the Buckingham model for the long-range correlationpolarization potential.

\section{Energy dependency of the correlation-polarization potential}

Figure 2 shows the influence of $b_{p o l}$ in the energy range $30-1000 \mathrm{eV}$. We observe that the DCSs at a small scattering angle decreases with increasing $b_{p o l}$, and this tendency rapidly saturates. We qualitatively found optimized values for $b_{p o l}$ as a function of electron energy $E$ using the results shown in Fig. 2, and we propose to use the following expression:

$$
b_{p o l}^{2}=\max [(E-20 \mathrm{eV}) / \mathrm{eV}, 1] .
$$

The DCSs with the proposed expression of $b_{\text {pol }}$ given in Eq. (5) and the DCSs with default $b_{\text {pol }}$ expression provided by ELSEPA given in Eq. (4) were compared with each other. The DCSs with the default energy-dependency parameter are higher than those with the suggested one by $15 \%$ to $28 \%$ at $0^{\circ}$.

TABLE II. List of Geant4-DNA examples used in this study.

\begin{tabular}{|c|c|c|}
\hline $\begin{array}{l}\text { Example } \\
\text { name }\end{array}$ & Physical quantity simulated by the example & References \\
\hline range & $\begin{array}{l}\text { Track length } \\
\text { Penetration } \\
\text { Projected range }\end{array}$ & 58 and 59 \\
\hline TestEm12 & Dose point kernel (DPK) & 60 and 61 \\
\hline microyz & Mean lineal energy & 56 and 57 \\
\hline clustering & $\begin{array}{l}\text { Single strand break (SSB) and double strand } \\
\text { break (DSB) yields from local energy } \\
\text { deposition only }\end{array}$ & 62 and 63 \\
\hline
\end{tabular}

The DCSs with suggested $b_{p o l}$ expression and Muffin-tin approximation are smaller than those of the free atom approximation by about $63 \%$ at $0^{\circ}$. This is in agreement with the prediction of Aouchiche et $a .^{25}$ that the DCSs at small angles are larger for the vapour-phase than for the liquid phase. No significant changes are observed for intermediate and large angles. These results thus support that the suggested energy-dependency expression is closer to the liquid water phase.

In summary, the correlation-polarization potential has a large influence at small scattering angles (e.g., about $60 \%$ at $0^{\circ}$ ), but it is negligible at intermediate and large scattering angles.

\section{Inelastic absorption strength}

In the case of inelastic absorption potential, we assumed that the absorption strength $A_{a b s}$ varies with energy because the probability of inelastic scattering depends on electron energy. This is shown in Fig. 3. There is no influence of absorption strength below $15 \mathrm{eV}$ due to the threshold of inelastic excitation. Above $15 \mathrm{eV}$, the high absorption strength increases the DCSs at a small scattering angle; however, at intermediate and large scattering angle above about $30^{\circ}$, the DCSs decrease with high absorption strength. The DCSs without the absorption strength are closer to the experimental data at the lowest energies; however, the absorption strength should be getting larger at higher energies in order to match with the experiments.

Figure 4 shows that a value of $A_{a b s}$ between 2 and 3 gives DCSs in reasonable agreement with the experimental data especially at intermediate and large angles above $32.5^{\circ}$, when the electron kinetic energy is above $100 \mathrm{eV}$.

We thus decided to adopt an absorption strength of 2.5 above $100 \mathrm{eV}$ and a reduced absorption strength below this energy. To minimize the discontinuity of the DCSs, we propose the following formula for the absorption strength $A_{a b s}$ as a function of the electron energy $E$ :

$$
A_{a b s}(E)=\min (E \times 2.5 \mathrm{eV} / 100 \mathrm{eV}, 2.5) .
$$

The absorption strength according to the electron energy $A_{a b s}(E)$ increases linearly with the electron energy in the range of 0 to $100 \mathrm{eV}$, and then its value is fixed to 2.5 above $100 \mathrm{eV}$.

In summary, we used the Muffin-tin approximation with the LDA correlation-polarization potential and a static polarizability of $1.457 \AA^{3}$, the Buckingham potential for the longrange correlation-polarization potential, and the suggested energy dependence for $b_{\text {pol }}$ given in Eq. (5). The inelastic absorption potential is considered with an energy gap $(\Delta)$ of $8.22 \mathrm{eV}$. The absorption strength $\left(A_{a b s}\right)$ of 2.5 is selected above $100 \mathrm{eV}$; otherwise, it varies as a function of energy based on the suggested expression of Eq. (6).

\section{B. Plausibility of the new electron elastic scattering models}

The DCSs obtained with the selected configuration (F-DF-FM-LDA-A) and with the optimized optical potentials show good agreement with experiments as shown in Fig. 5. 
TABLE III. References used for the "range" simulations. Each column indicates reference paper, calculation method or model, phase of target medium, simulated quantity, and energy range.

\begin{tabular}{|c|c|c|c|c|}
\hline References & Methods and models & $\begin{array}{l}\text { Target } \\
\text { phase }\end{array}$ & Quantity & Energy range \\
\hline $\begin{array}{l}\text { Pages et al. } \\
(1972)^{64}\end{array}$ & $\begin{array}{l}\text { Bethe formula }{ }^{65} \text { for the collision energy loss with the Sternheimer density-effect } \\
\text { correction }{ }^{66} \\
\text { Cross section generated by the Koch-Motz formula }{ }^{67} \text { for the radiative energy loss }\end{array}$ & $\begin{array}{l}\text { No mention } \\
\text { about phase }\end{array}$ & Track length & $10 \mathrm{keV}-100 \mathrm{MeV}$ \\
\hline Watt $(1996)^{68}$ & $\begin{array}{l}\text { Continuous slowing down approximation }(\mathrm{CSDA}) \text { range }^{70, \mathrm{a}} \\
\text { Modified Bethe theory given in ICRU } 37^{69}>10 \mathrm{keV} \\
\text { Deduction based on the theoretical results of Ashley }{ }^{70} \text { and empirical evaluations }{ }^{71,72} \\
<10 \mathrm{keV}\end{array}$ & $\begin{array}{l}\text { Liquid } \\
\text { water }\end{array}$ & Track length & $15 \mathrm{eV}-30 \mathrm{MeV}$ \\
\hline $\begin{array}{l}\text { Akkerman and } \\
\text { Akkerman } \\
(1999)^{73}\end{array}$ & $\begin{array}{l}\text { CSDA range }{ }^{69} \text { with and without exchange } \\
\text { Inelastic cross section based on dielectric theory }{ }^{74} \text { and elastic cross sections based on } \\
\text { partial wave analysis }\end{array}$ & $\begin{array}{l}\text { Liquid } \\
\text { water }\end{array}$ & $\begin{array}{l}\text { Track } \\
\text { length }^{\mathrm{b}}\end{array}$ & $50 \mathrm{eV}-10 \mathrm{keV}$ \\
\hline $\begin{array}{l}\text { Meesungnoen } \\
\text { et al. }(2002)^{77}\end{array}$ & $\begin{array}{l}\text { MCTS code (TRACPRO) } \\
\text { Elastic and inelastic cross sections for sub-excitation processes are based on scaled } \\
\text { empirical data for amorphous water to account for differences between solid and } \\
\text { liquid-phase. Recombination and dissociative attachment are taken into account } \\
\text { as well }{ }^{79}\end{array}$ & $\begin{array}{l}\text { Liquid } \\
\text { water }\end{array}$ & Penetration & $0.2 \mathrm{eV}-150 \mathrm{keV}$ \\
\hline $\begin{array}{l}\text { Pimblott and } \\
\text { Siebbeles }(2002)^{80}\end{array}$ & $\begin{array}{l}\text { MCTS code (MOCA) })^{81,82} \text { and CSDA range }{ }^{69} \\
\text { Elastic cross section based on partial wave method }{ }^{83-85} \\
\text { Inelastic cross sections based on experimental dipole oscillator strength }\end{array}$ & $\begin{array}{l}\text { Liquid } \\
\text { water }\end{array}$ & $\begin{array}{l}\text { Track length }^{\mathrm{c}} \\
\text { Penetration }\end{array}$ & $70 \mathrm{eV}-100 \mathrm{keV}$ \\
\hline $\begin{array}{l}\text { Wilson et al. } \\
(2004)^{2}\end{array}$ & $\begin{array}{l}\text { MCTS code (PITS) } \\
\text { Inelastic cross section based on dielectric theory (Dingfelder-GSF model) for liquid } \\
\text { water }^{13} \text { and elastic cross section based on the experiments and NIST data for vapour } \\
\text { water }^{89}\end{array}$ & $\begin{array}{l}\text { Liquid } \\
\text { water }\end{array}$ & $\begin{array}{l}\text { Track length } \\
\text { Penetration }\end{array}$ & $20 \mathrm{eV}-100 \mathrm{keV}$ \\
\hline $\begin{array}{l}\text { Uehara and } \\
\text { Nikjoo }(2006)^{90}\end{array}$ & $\begin{array}{l}\text { MCTS code (KURBUC) } \\
\text { Water vapour cross sections for ionization and excitation }{ }^{1} \text { are compiled from different } \\
\text { sources and elastic cross section based on the Rutherford formula for vapour water } \\
\text { with a screening parameter }{ }^{44} \\
\text { Vibrational excitation and multi-step thermalization process are taken into account }{ }^{42}\end{array}$ & $\begin{array}{l}\text { Vapour } \\
\text { water }\end{array}$ & Penetration & $0.1 \mathrm{eV}-100 \mathrm{keV}$ \\
\hline $\begin{array}{l}\text { Plante and } \\
\text { Cucinotta } \\
(2009)^{91}\end{array}$ & $\begin{array}{l}\text { MCTS code (RETRACKS) } \\
\text { Ionization cross section of Rudd's model }{ }^{92} \text { below } 50 \mathrm{keV} \text { and Seltzer's equation }{ }^{93} \\
\text { above } 50 \mathrm{keV} \\
\text { Excitation model of Kaplan and Sukhonosov }{ }^{94} \text { and Kutcher and Green }{ }^{95} \text { below } 100 \\
\mathrm{eV} \text { and above, respectively } \\
\text { Elastic cross section based on the experimental data } \\
\text { Brenner and Zaider below } 200 \mathrm{eV},{ }^{96} \text { and Rutherford cross section above } 200 \mathrm{eV}^{44} \\
\text { Vibrational excitation, }{ }^{55} \text { dissociative attachment, }{ }^{79} \text { and bremsstrahlung process } \\
\text { taken into account }\end{array}$ & $\begin{array}{l}\text { Liquid } \\
\text { water }\end{array}$ & Penetration & $0.1 \mathrm{eV}-10 \mathrm{MeV}$ \\
\hline $\begin{array}{l}\text { Wiklund et al. } \\
(2011)^{97}\end{array}$ & $\begin{array}{l}\text { MCTS code } \\
\text { Inelastic cross section based on dielectric theory (Dingfelder-GSF model) for liquid } \\
\text { water }{ }^{13} \text { and elastic cross section generated by ELSEPA (P-DF-FM-Buckingham) }{ }^{28} \\
\text { with density scaling to account for the liquid-phase } \\
\text { Cross sections for dissociative attachment are included }\end{array}$ & $\begin{array}{l}\text { Liquid } \\
\text { water }\end{array}$ & $\begin{array}{l}\text { Track length } \\
\text { Penetration }\end{array}$ & $10 \mathrm{eV}-10 \mathrm{keV}$ \\
\hline $\begin{array}{l}\text { ICRU Report } 90 \\
(2014)^{98}\end{array}$ & $\begin{array}{l}\text { CSDA range }^{69} \\
\text { Stopping power based on ESTAR }\end{array}$ & $\begin{array}{l}\text { Liquid } \\
\text { water }\end{array}$ & Track length & $1 \mathrm{keV}-1 \mathrm{GeV}$ \\
\hline $\begin{array}{l}\text { Emfietzoglou } \\
\text { et al. }(2017)^{100}\end{array}$ & $\begin{array}{l}\text { In-house } \mathrm{MC} \text { track-structure code }{ }^{101} \\
\text { Inelastic cross sections based on the dielectric theory (ECN model })^{16} \text { for liquid water } \\
\text { and elastic cross sections based on screened Rutherford model }\end{array}$ & $\begin{array}{l}\text { Liquid } \\
\text { water }\end{array}$ & $\begin{array}{l}\text { Track length } \\
\text { Penetration }\end{array}$ & $10 \mathrm{eV}-10 \mathrm{keV}$ \\
\hline
\end{tabular}

${ }^{\mathrm{a}}$ Integrating the inverse of the total stopping power.

${ }^{\mathrm{b}} \mathrm{CSDA}$ range with exchange process was used in this study.

${ }^{\mathrm{c}}$ Track length from the MC method.

However, we can observe that the disagreements with the experimental data below $20 \mathrm{eV}$ at small and intermediate scattering angles are not only present in the ELSEPA model but also in the Champion and CPA-100 models. We can thus conclude that the partial-wave approximation has a limited accuracy on the calculation of electron cross section below $20 \mathrm{eV}$. This is expected as the exchange potential cannot accurately predict the interaction of electrons below 1 Hartree energy $(27.21 \mathrm{eV}){ }^{102}$ Moreover, the DCSs at $0^{\circ}$ are overestimated, considering the expected difference between vapour and liquid water data above $500 \mathrm{eV}$.

Globally, the DCSs calculated in this study are closer to the measurements than the default ICRU 77 recommendation, SR, USR, Champion, and CPA-100 models over the entire 


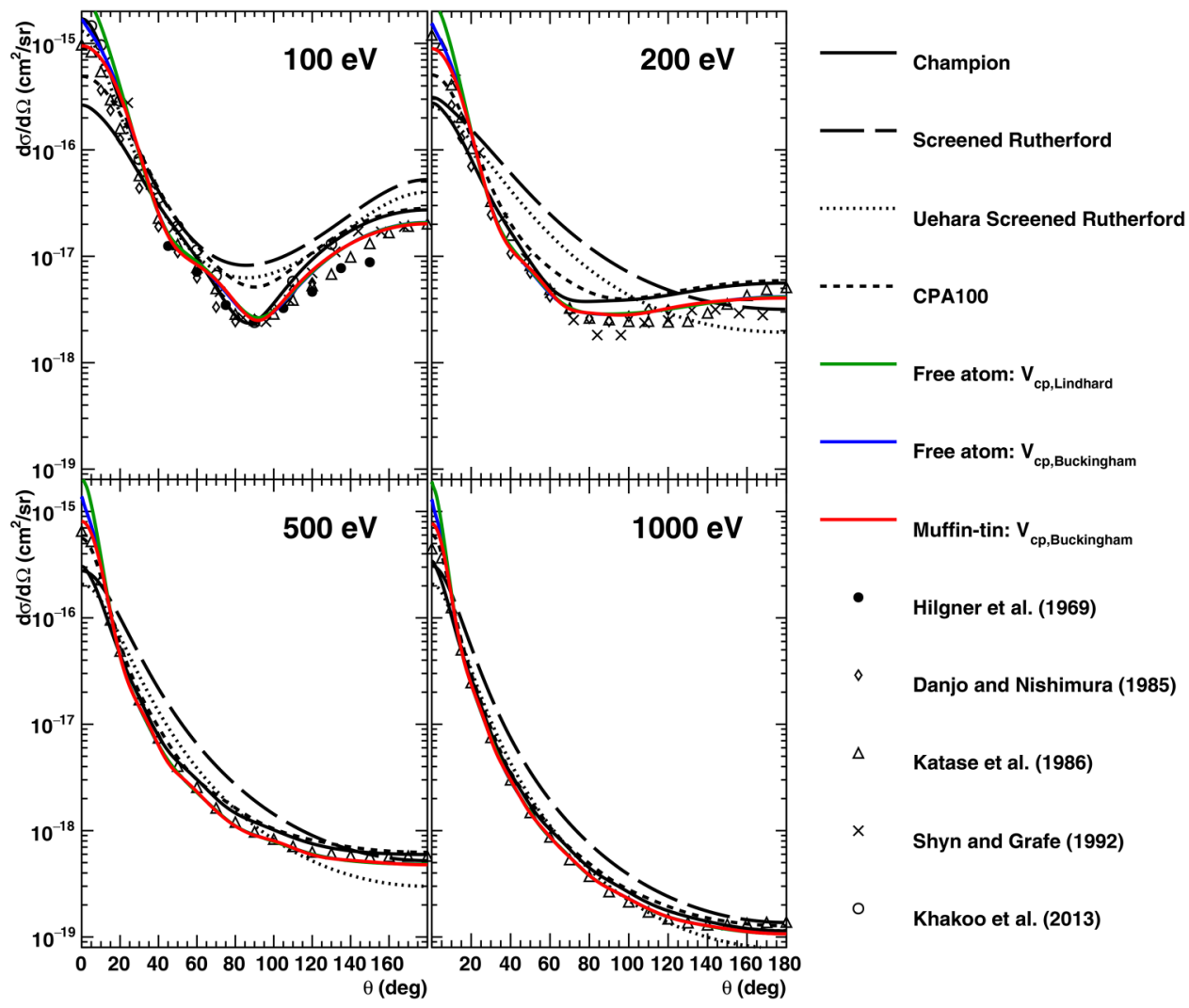

FIG. 1. DCSs obtained using the "F-DF-FM-LDA" configuration and the correlation-polarization potential in the energy range $100-1000 \mathrm{eV}$ using the Lindhard model (green) or the Buckingham model (blue) with free atom approximation. The red lines indicate the DCSs with Buckingham model and Muffin-tin approximation.

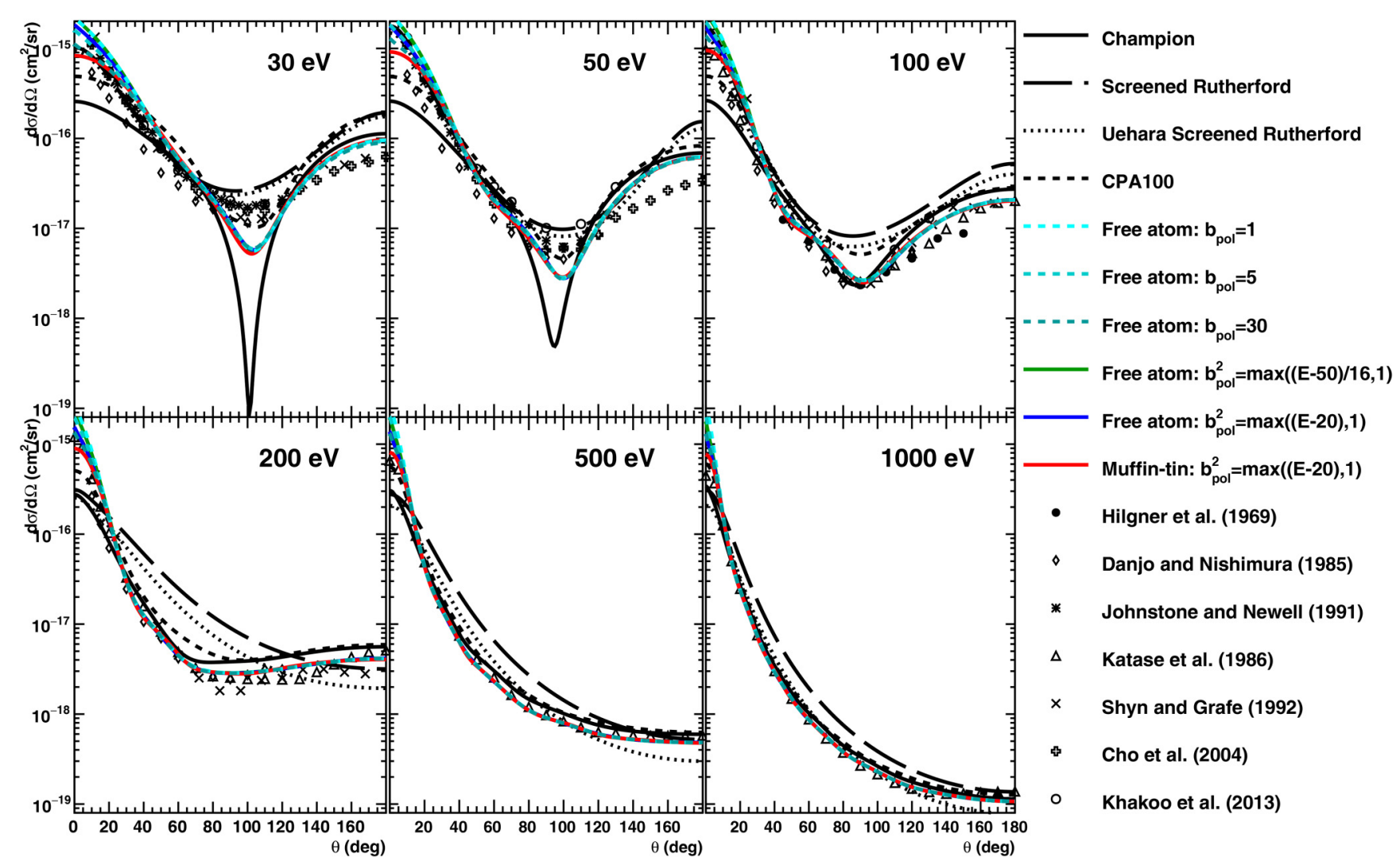

FIG. 2. DCSs according to the different $b_{p o l}$ values in the energy range 30-1000 eV. The cyan to green dashed lines show the DCSs with $b_{p o l}$ values ranging from 1 to 30, the green lines indicate the DCSs with the default expression of $b_{p o l}$ provided in ELSEPA, and the blue and red lines represent the DCSs of the proposed expression (4) with free atom approximation and Muffin-tin approximation, respectively. 

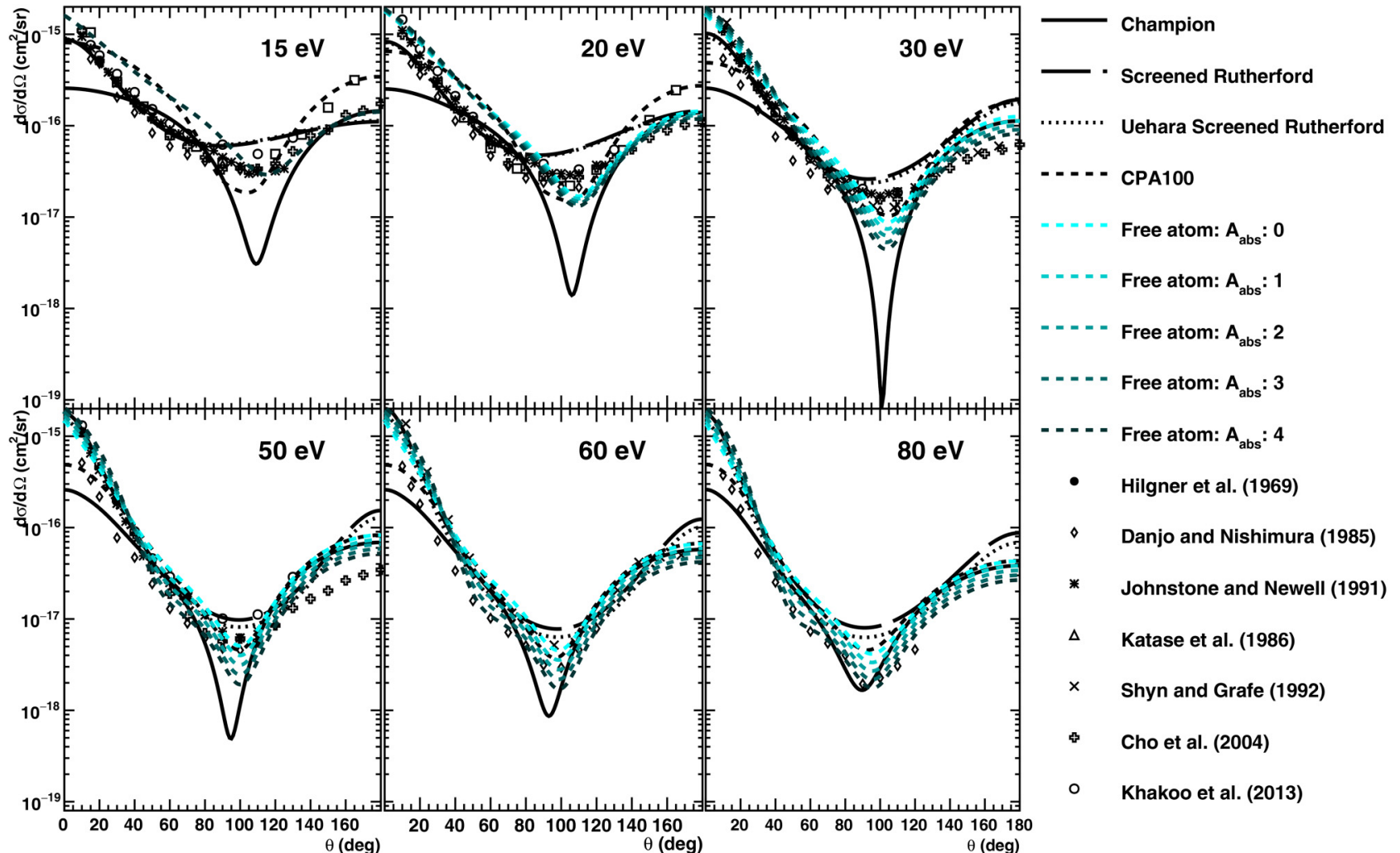

FIG. 3. DCSs obtained for different values of $A_{a b s}$ in the energy range $15-80 \mathrm{eV}$. The light cyan line indicates the DCS without inelastic absorption, and the dark cyan line indicates the highest absorption strength.

energy range. In particular, the cross sections are much improved at low energy and intermediate angle. The DCSs obtained with the Muffin-tin approach are lower than those of the experimental data of vapour water at a small scattering angle by about $60 \%$ in agreement with the expected difference between vapour- and liquid-phases.

Figure 6 shows the comparison of TECSs and MTCSs calculated by ELSEPA, with current Geant4-DNA models

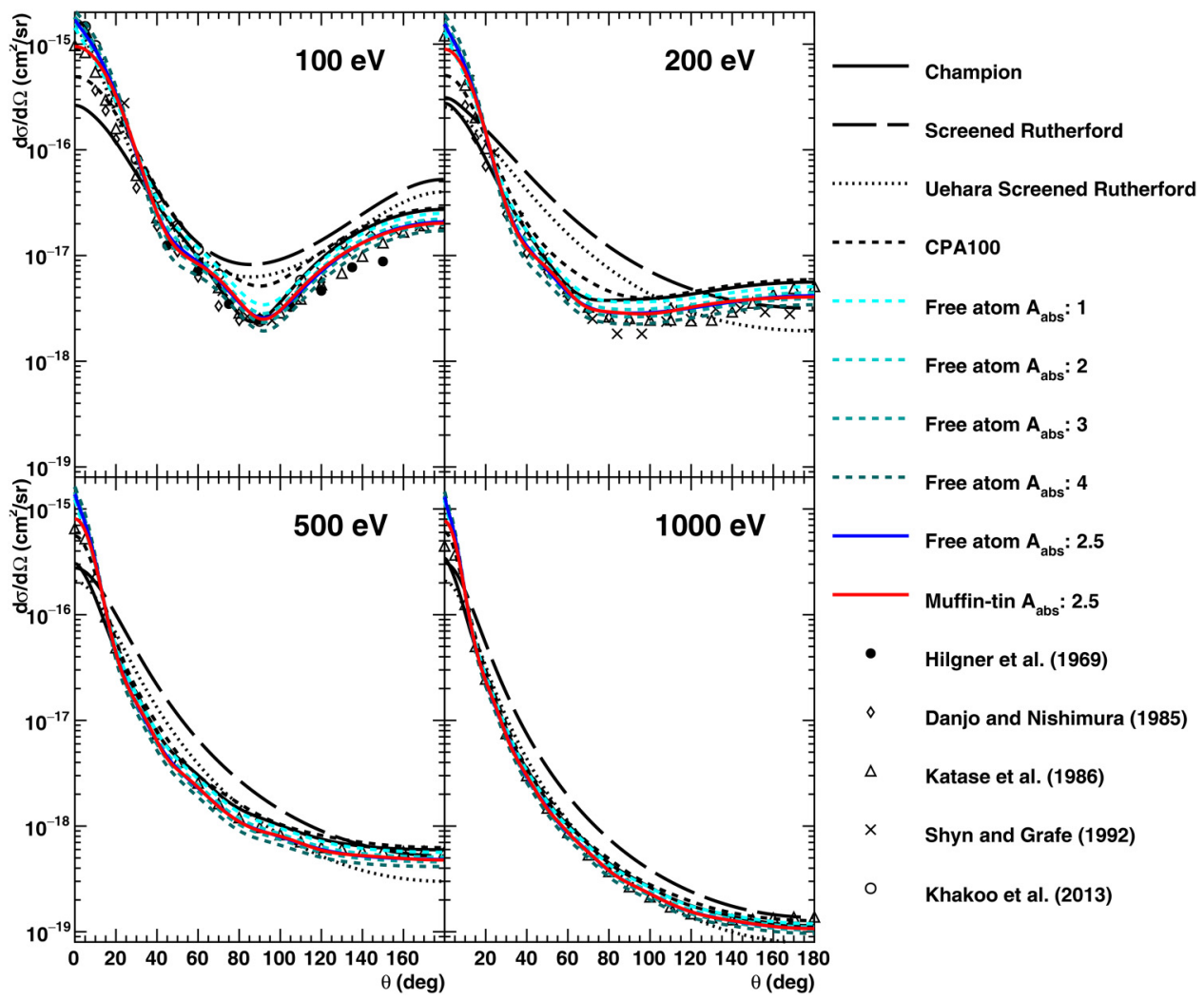

FIG. 4. DCSs obtained for different values of $A_{a b s}$ in the energy range $100-1000 \mathrm{eV}$. The light cyan dashed line indicates the DCS without inelastic absorption, and the dark cyan dashed line indicates the highest absorption strength. The blue and red lines represent the DCSs of the optimal inelastic absorption strength with free atom approximation and Muffin-tin approximation, respectively. 


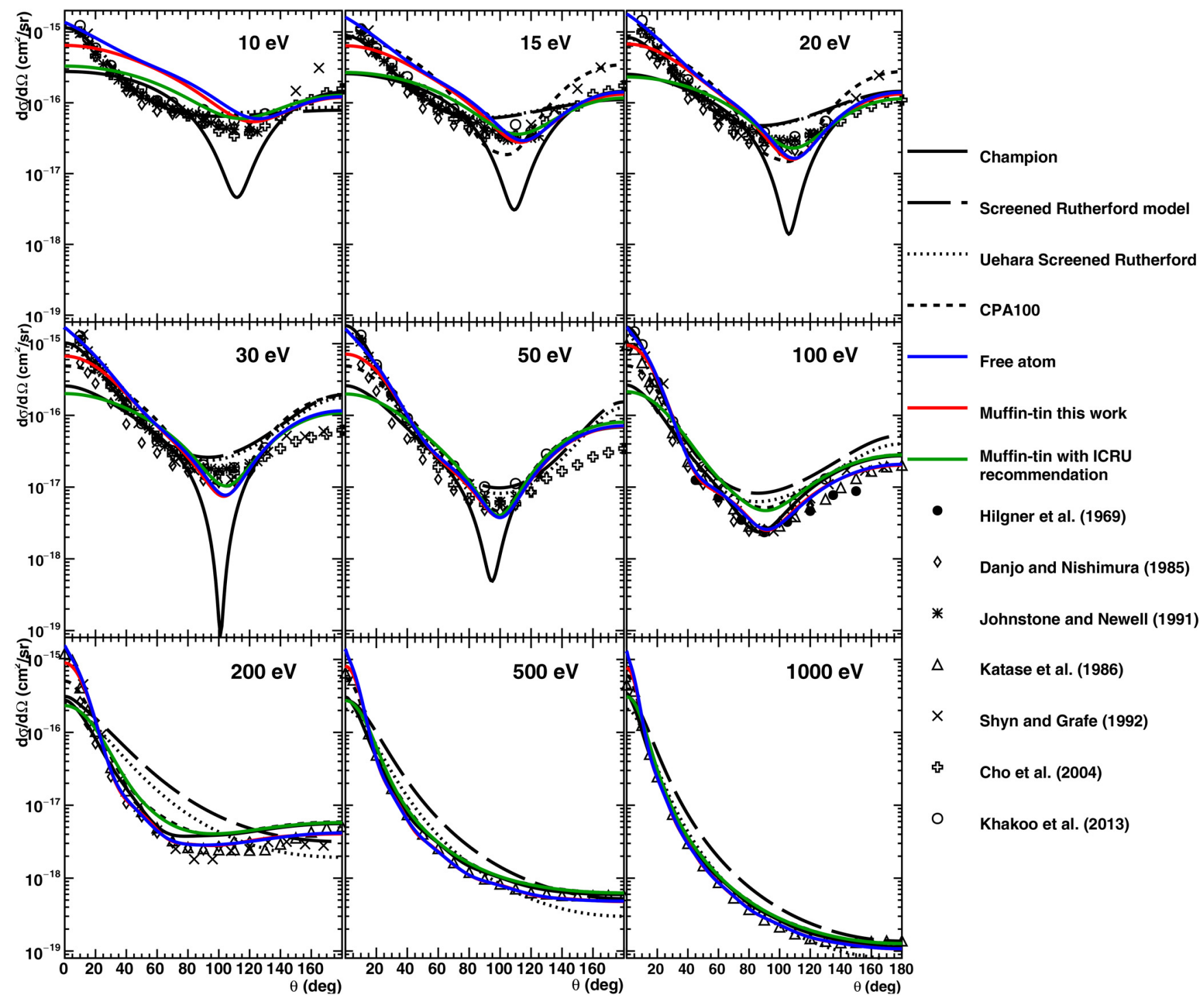

FIG. 5. DCSs obtained for the free atom approximation with optimized optical potentials (blue line), and Muffin-tin approximation with optimized optical potentials (red line) and ICRU recommendation (green line). The experimental data measured in vapour-phase water are indicated as well.

and the experimental data in the vapour-phase. The MTCSs of the SR and the USR models below $200 \mathrm{eV}$ are slightly distorted because the SR and USR models employ independent fitting formulas proposed by Brenner and Zaider. ${ }^{96}$ Even though it is observed that the cross sections are overestimated at even lower energy below $30 \mathrm{eV}$, the TECS and MTCS of ELSEPA are perfectly following the tendency of the USR model and experiments on the entire energy range.

Our TECS is relatively larger than ICRU 77 recommendation and is closer to the CPA-100 model, while the TECS of ICRU 77 is closer to the Champion model. However, the MTCS of the present work shows a better agreement with the experimental data than the other models, especially above $30 \mathrm{eV}$.

\section{Geant4-DNA examples}

\section{Range simulations}

Figure 7 shows the average track length simulated values $\left(10^{6}\right.$ histories) and literature references. It has to be noted that the model of CPA-100 available in the Geant4-DNA "option 6" constructor considers indeed small energy losses in elastic scattering. ${ }^{15}$ The track length is only affected by energy losses mainly with inelastic scattering except for "option 6." The track lengths of Wilson et al. ${ }^{2}$ and Wiklund et al., ${ }^{97}$ which use the same inelastic model (the Dingfelder-GSF dielectric model for liquid water based on the Born approximation), show a similar tendency. Moreover, the results of track length between "default options" and "ELSEPA options" are the same except for "option 6" because of the non-zero energy loss during elastic scattering assumed by "option 6." Without this energy loss, the results of "option 6 ELSEPA" show the same values as "option 6." As expected, the track lengths with the CSDA approach look shorter than the other approaches, such as the MC method, because the low energy limit considered in the CSDA approach is almost always larger than the tracking cut used in the MC simulations.

The penetrations of Geant4-DNA show good agreement with the results proposed by Pimblott and Siebbeles, ${ }^{80}$ Wiklund et al., ${ }^{97}$ and Emfietzoglou et al. ${ }^{100}$ However, the 


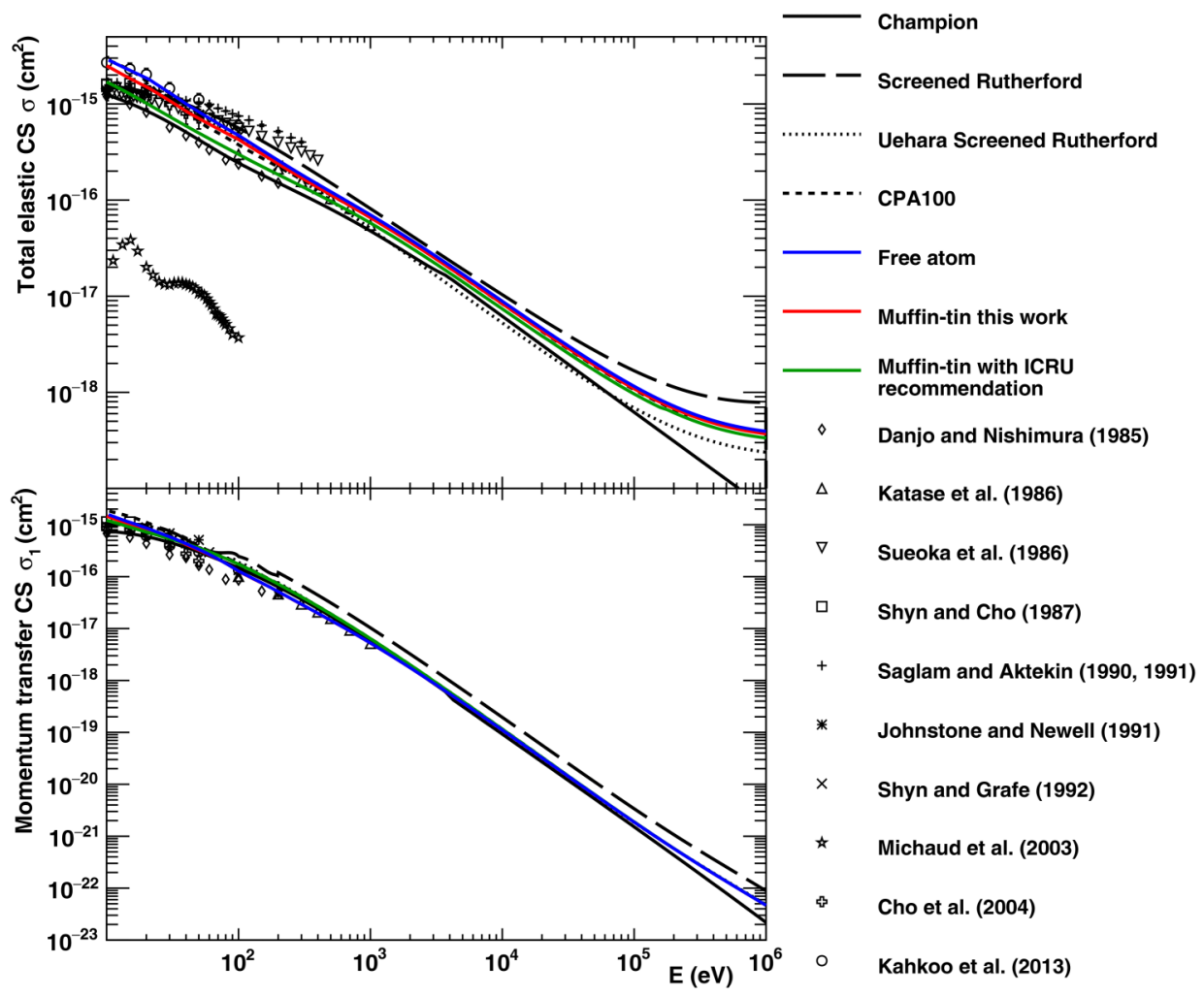

FIG. 6. TECSs (upper) and MTCSs (below) for electron elastic scattering in liquid water plotted from $10 \mathrm{eV}$ up to $1 \mathrm{MeV}$ as a function of electron incident energy. The blue curves show the cross sections calculated with the free atom approximation, and the red and green curves represent the cross sections calculated with the Muffin-tin approximation and ICRU recommendation, respectively.

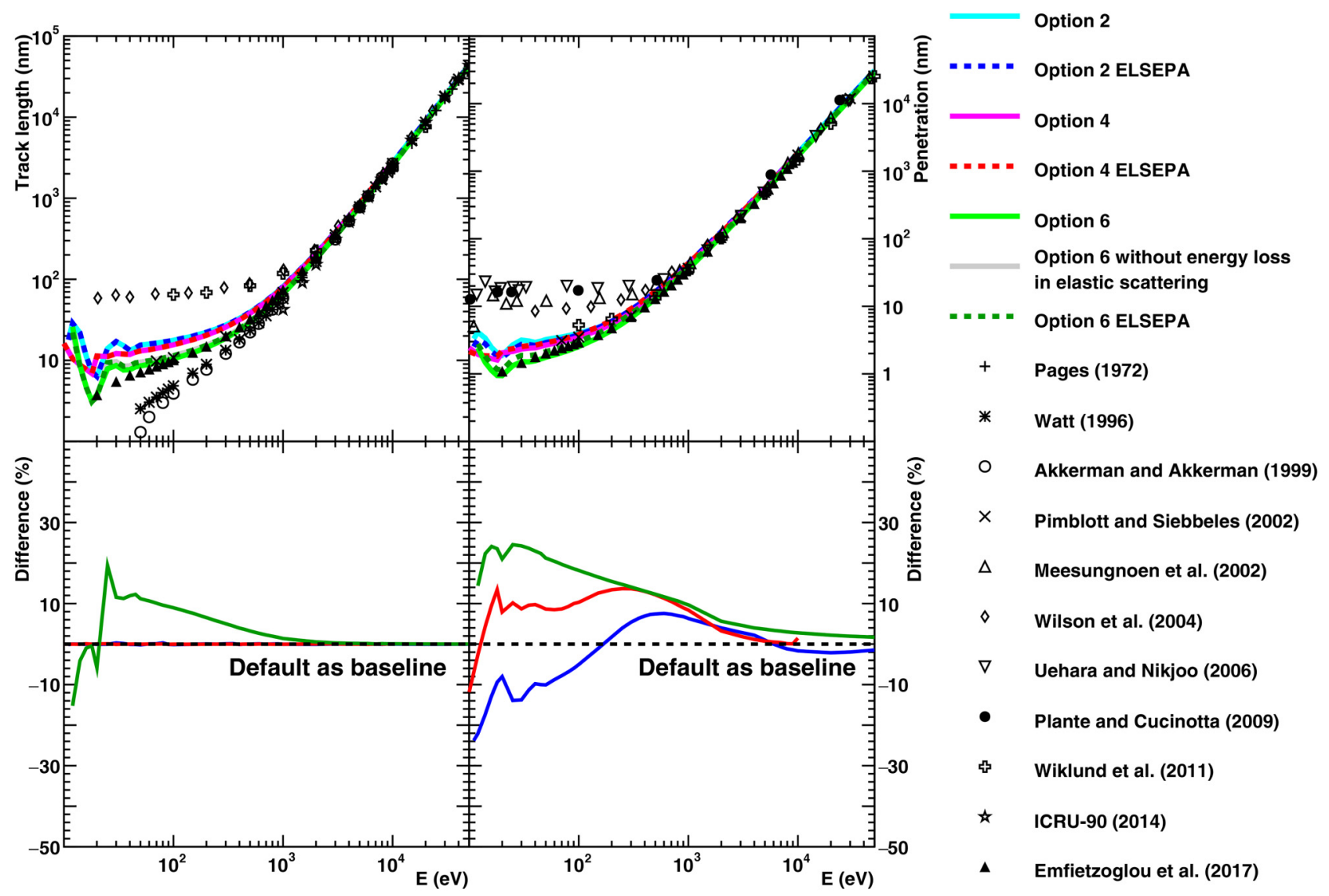

FIG. 7. Simulation results of track length (upper left) and penetration (upper right) as a function of incident energy, using Geant4-DNA physics constructors "option 2" (cyan solid), "option 4" (magenta solid), "option 6" (light green solid), "option 6" without energy loss in elastic scatterings (gray solid) constructors, and simulation results obtained with the "option 2 ELSEPA" (blue dashed), "option 4 ELSEPA" (red dashed), "option 6 ELSEPA" (green dashed) constructors in which elastic scattering is simulated using our new ELSEPA-based elastic model. The markers represent the reference data listed in Table III. The bottom figures show the relative differences between "default options" and the "ELSEPA options" constructors, with the "default options" constructor as baseline. 
other approaches show higher penetration ranges than our results. The relative differences between the "default options" and the "ELSEPA options" are less than 20\%, and the differences are getting smaller with the increase of initial energy because the contribution of the elastic scattering is relatively small at high energy.

From the simulation results shown in Fig. 7, we can draw the following general conclusions with respect to the penetration of electrons:

(1) More elastic scatterings decrease the penetration.

- This conclusion looks intuitively reasonable; however, it is not observed in the simulations because the penetrations are also affected by the values of scattering angles (obtained from DCSs).

- For example, the TECSs of the Champion and USR elastic models in "option 2" and "option 4," respectively, are almost always lower than that of the ELSEPA-based model over the entire energy range; however, the influence of the elastic model on the penetration for "option 2" and "option 4" (see the inset of Fig. 7) depends on the incident energy.

- We can thus conclude that the penetration of electrons depends not only on the magnitude of the TECS but also on the distribution of scattering angles.

(2) Smaller scattering angles induce larger penetration.

- In order to consider both the influence of the number of elastic scatterings and of the scattering angles values simultaneously, we assume that the MTCS better reflects the influence of elastic scattering on penetration. The MTCS can be described by the integration of $(1-\cos \theta) \frac{d \sigma}{d \Omega}$; in other words, a model with a lower MTCS causes a smaller scattering angle compared to a model with a higher MTCS and the same TECS.

- The MTCS of the ELSEPA-based model is smaller than that of the USR model in the energy range $15 \mathrm{eV}-5000 \mathrm{eV}$, and this tendency is compatible with the observation that the ELSEPA-based model leads to longer penetration (see the inset of the bottom panel in Fig. 7, "option 4" and "option 4 ELSEPA" curves).

- The MTCSs of the ELSEPA-based and Champion models cross two times, at $80 \mathrm{eV}$ and $4 \mathrm{keV}$, in "option 2." However, we can observe such crossings in the corresponding penetration at $200 \mathrm{eV}$ and $5 \mathrm{keV}$. The energy shift is caused by energy losses due to inelastic interactions. We can thus assume that the influence of electrons in the $10-80 \mathrm{eV}$ and $200 \mathrm{eV}-4 \mathrm{keV}$ energy ranges on the penetration is more important than in the $80-200 \mathrm{eV}$ and $4-5 \mathrm{keV}$ energy ranges.

\section{Dose Point Kernel simulations}

Figures 8 and 9 show the results of dose point kernel (DPK) simulations, and the relative differences between the DPKs with and without the new elastic model, respectively. In particular, the relative differences $\Delta(r)$ as shown in
Fig. 9 were calculated based on the comparison method suggested by Maigne et al. ${ }^{103}$ in order to reduce statistical fluctuations due to the low energy deposition in the tail of distributions:

$$
\Delta(r)=\frac{\delta E_{E L}(r)-\delta E_{d e f}(r)}{\max \left(\delta E_{E L}, \delta E_{d e f}\right)} \times 100(\%),
$$

where $\delta E_{E L}(r)$ and $\delta E_{d e f}(r)$ represent energy deposition in a shell of radius $r$, calculated with the "ELSEPA options" and "default options," respectively.

With the same logic as for penetration results, the electrons transported with "option 4 ELSEPA" and "option 6 ELSEPA" are more diffusive along the radial distance than those transported with default "option 4" and "option 6" in the entire energy range, and the tendency of "option 2" depends on the incident energy. In general, the influence of the new model is less pronounced at high energy due to the smaller contribution of elastic scattering.

According to the study of Aouchiche et al., ${ }^{25}$ the DCSs of the liquid phase water and vapour phase water are similar and differ for a small scattering angle. That means that the MTCS of liquid water is smaller than that of vapour water, and electrons are thus more diffusive in liquid water. We can discuss about the phase-influence comparing the calculated elastic cross section with USR model because the USR model basically considered vapour phase water. In the Geant4-DNA simulations (especially DPK results), the ELSEPA model is always more diffusive than simulations obtained with the USR model.

\section{Microdosimetry simulations}

For the sphere of $2 \mathrm{~nm}$ in diameter, frequency-mean lineal energies $y_{F}$ calculated with "option 2" and "option 4" are very similar as shown in Fig. 10. However, the results of "option 6" are almost half of the other options due to the energy loss in elastic scattering. Without the energy loss, the $y_{F}$ of "option 6" is higher than the other options by about $20 \%-40 \%$, and we can assume that the large inelastic cross section of "option 6" is mainly responsible for this difference. The results of "option 2" change by less than $1 \%$ with the ELSEPA-based elastic model. In the case of "option 4," the ELSEPA-based elastic model reduces $y_{F}$ by about $3 \%$. The results of "option 6 ELSEPA" are significantly different with "option 6"; however, they decrease $y_{F}$ by about $5 \%$ in comparison with "option 6" without energy loss.

$y_{F}$ values for the sphere of $10 \mathrm{~nm}$-diameter have a similar tendency with that of $2 \mathrm{~nm}$-diameter; however, the effect of the ELSEPA-based model for the $10 \mathrm{~nm}$ sphere is larger compared to the $2 \mathrm{~nm}$ sphere case because the differences of the distributions between the "ELSEPA options" and "default options" at $10 \mathrm{~nm}$ are larger than that of the $2 \mathrm{~nm}$ sphere in the energy range of $500 \mathrm{eV}-10 \mathrm{keV}$.

"Option 2" is not affected much; "option 4" and "option 6 " results are reduced using the ELSEPA-based elastic model in both the $2 \mathrm{~nm}$ and $10 \mathrm{~nm}$ spheres. However, the relative differences are less than $5 \%$. 
$50 \mathrm{eV}$
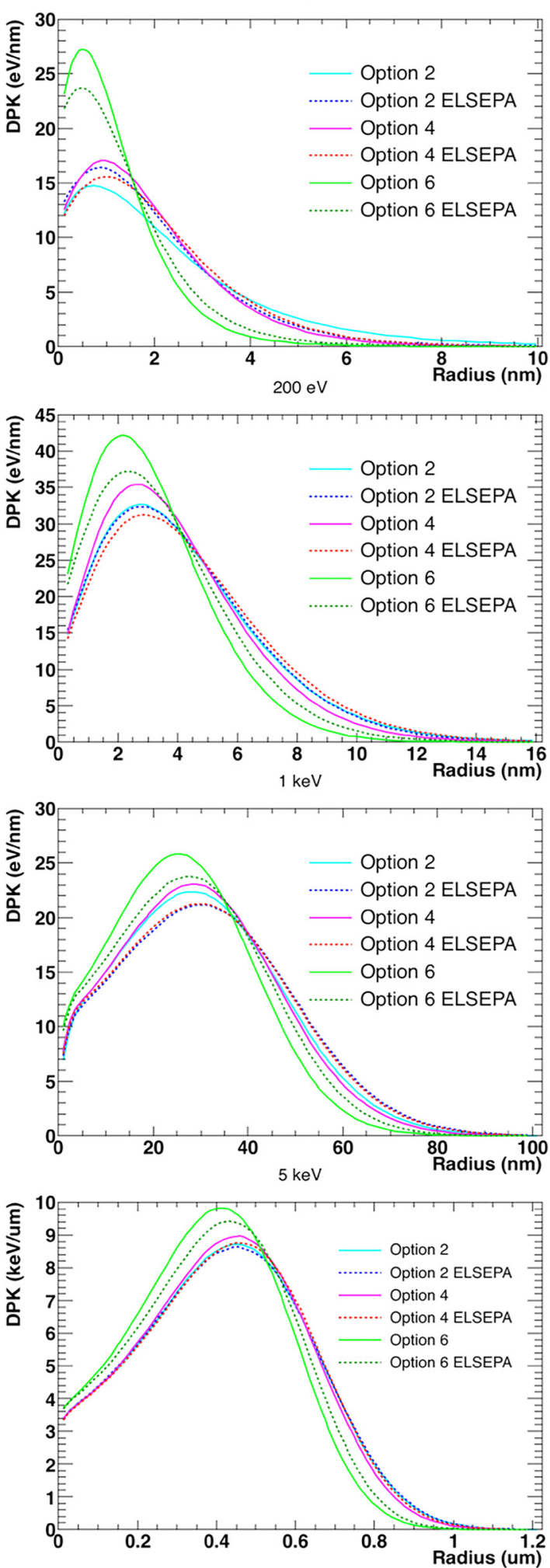

$100 \mathrm{eV}$
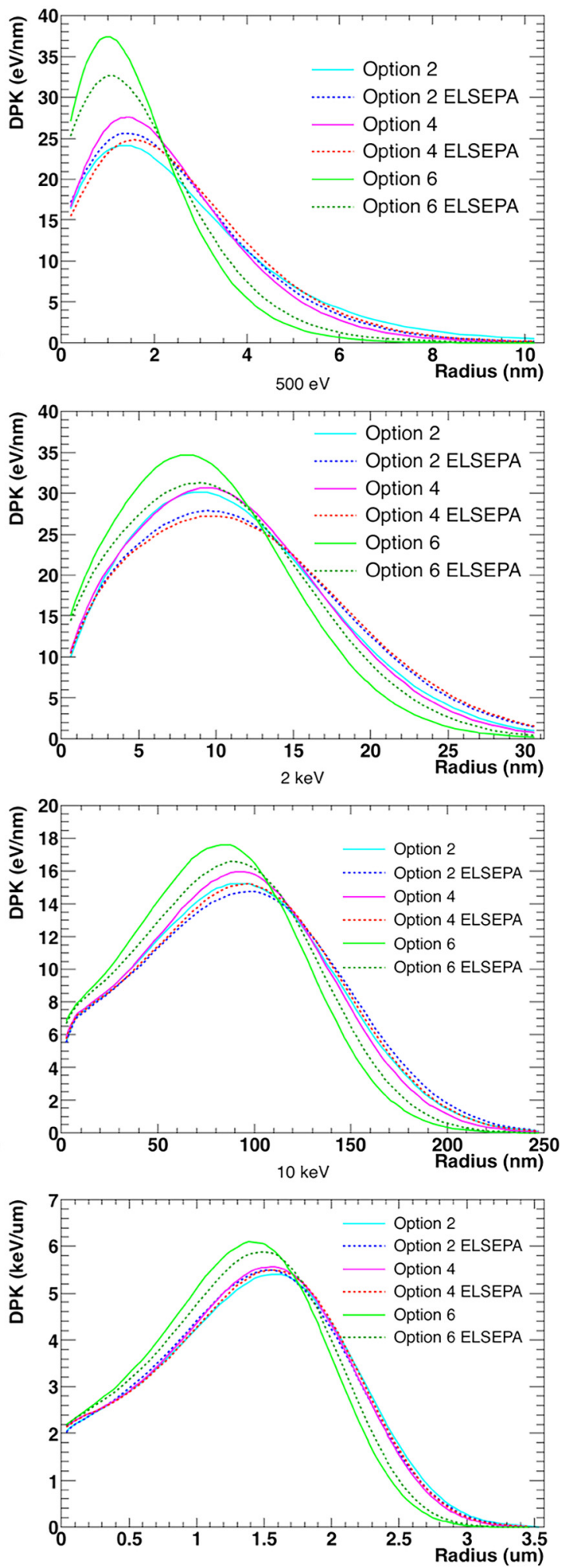

FIG. 8. DPKs in the energy range $50 \mathrm{eV}-10 \mathrm{keV}$ for default "option 2" (cyan solid), "option 4" (magenta solid), and "option 6" (light green solid) constructors, and "option 2 ELSEPA" (blue dashed), "option 4 ELSEPA" (red dashed), and "option 6 ELSEPA" (green dashed) constructors which include the ELSEPA-based elastic model.

\section{Clustering simulations}

Figure 11 shows the single strand break (SSB) and double strand break (DSB) yields normalized to energy deposition in arbitrary unit. With the increase of the incident energy, the SSB yield increases and the DSB yield decreases in agreement with other recent studies ${ }^{104,105}$ because the linear energy transfer (LET) of electrons is getting lower, up to an electron energy of $1 \mathrm{MeV}$. 
$50 \mathrm{eV}$
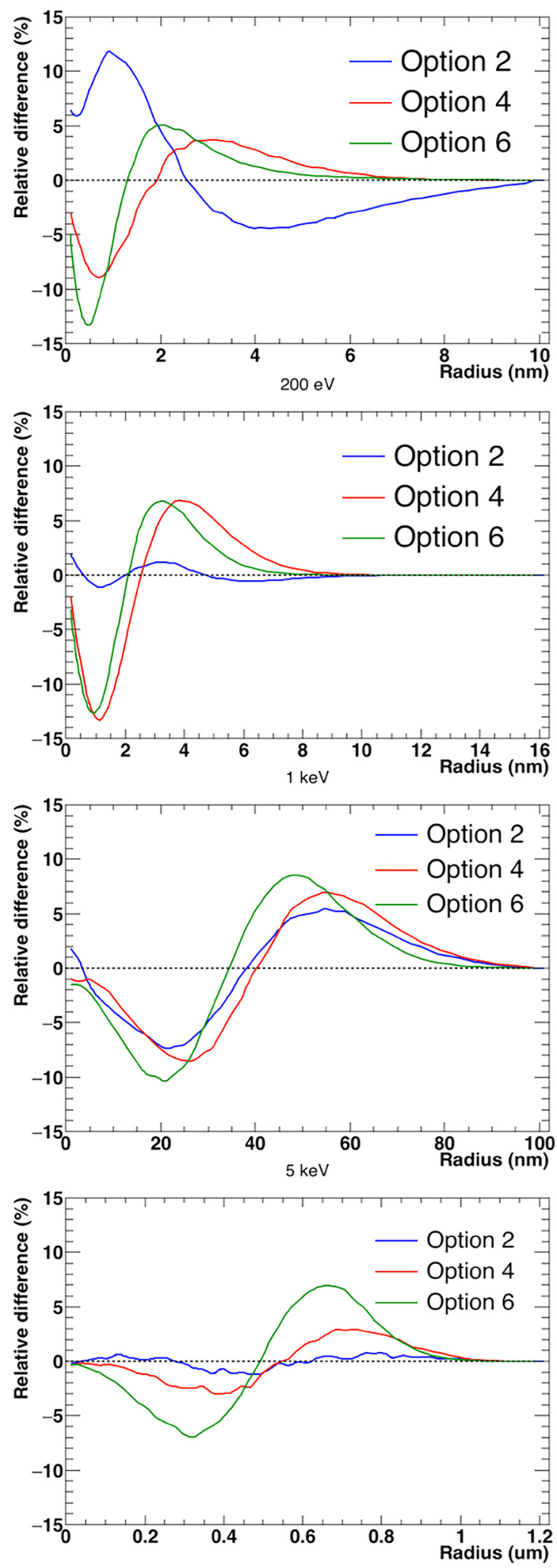

$100 \mathrm{eV}$
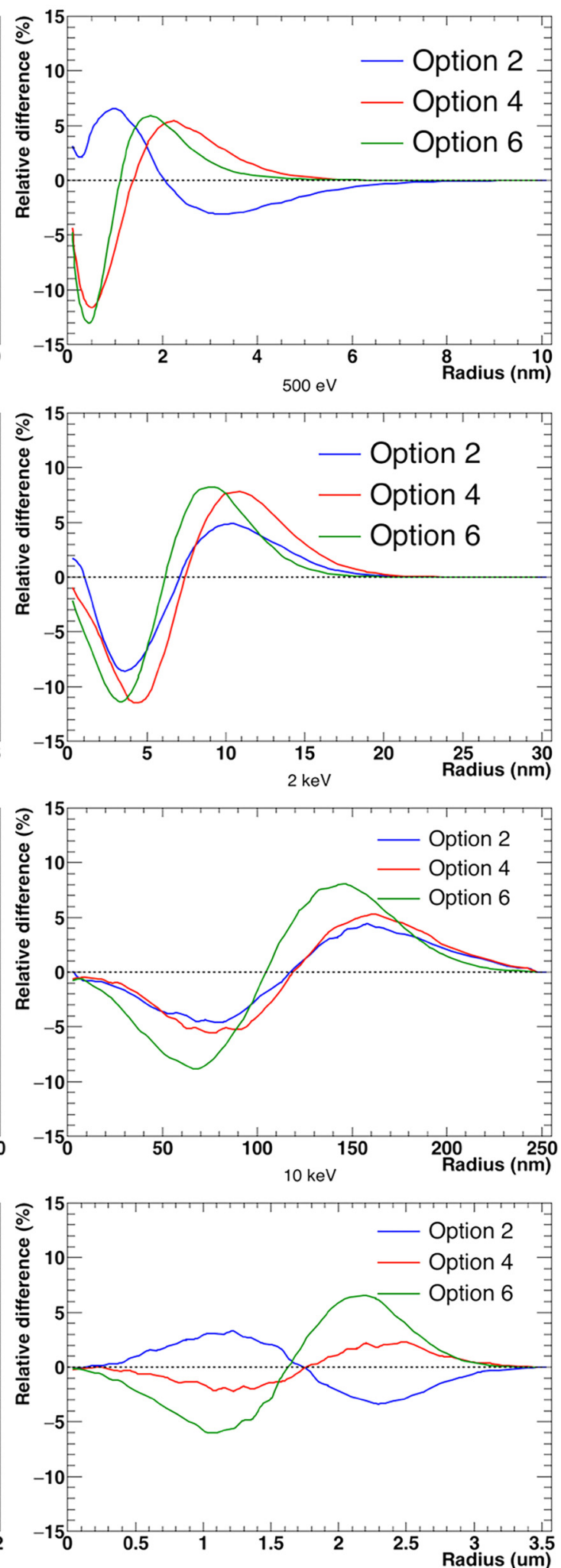

FIG. 9. Relative differences between "default options" and "ELSEPA options" in the energy range $50 \mathrm{eV}-10 \mathrm{keV}$, with the "default options" as references.

The DSB yields of all "default options" are higher than "ELSEPA options," up to $1.3 \%, 7.1 \%$, and $5.8 \%$ for "option 2 ," "option 4," and "option 6," respectively. Indeed, as already shown, the "default options" are less diffusive than "ELSEPA options" ("option 4" and "option 6" over the entire energy range, "option 2" in the energy range 500
eV-10 keV); in other words, electrons deliver energies in a more concentrated area. The DSB values obtained for "option 6" (with or without ELSEPA) are larger than for the two other options ("option 2" and "option 6"). These results should be considered with care however as we recently commented that "option 4" is currently the most accurate option 


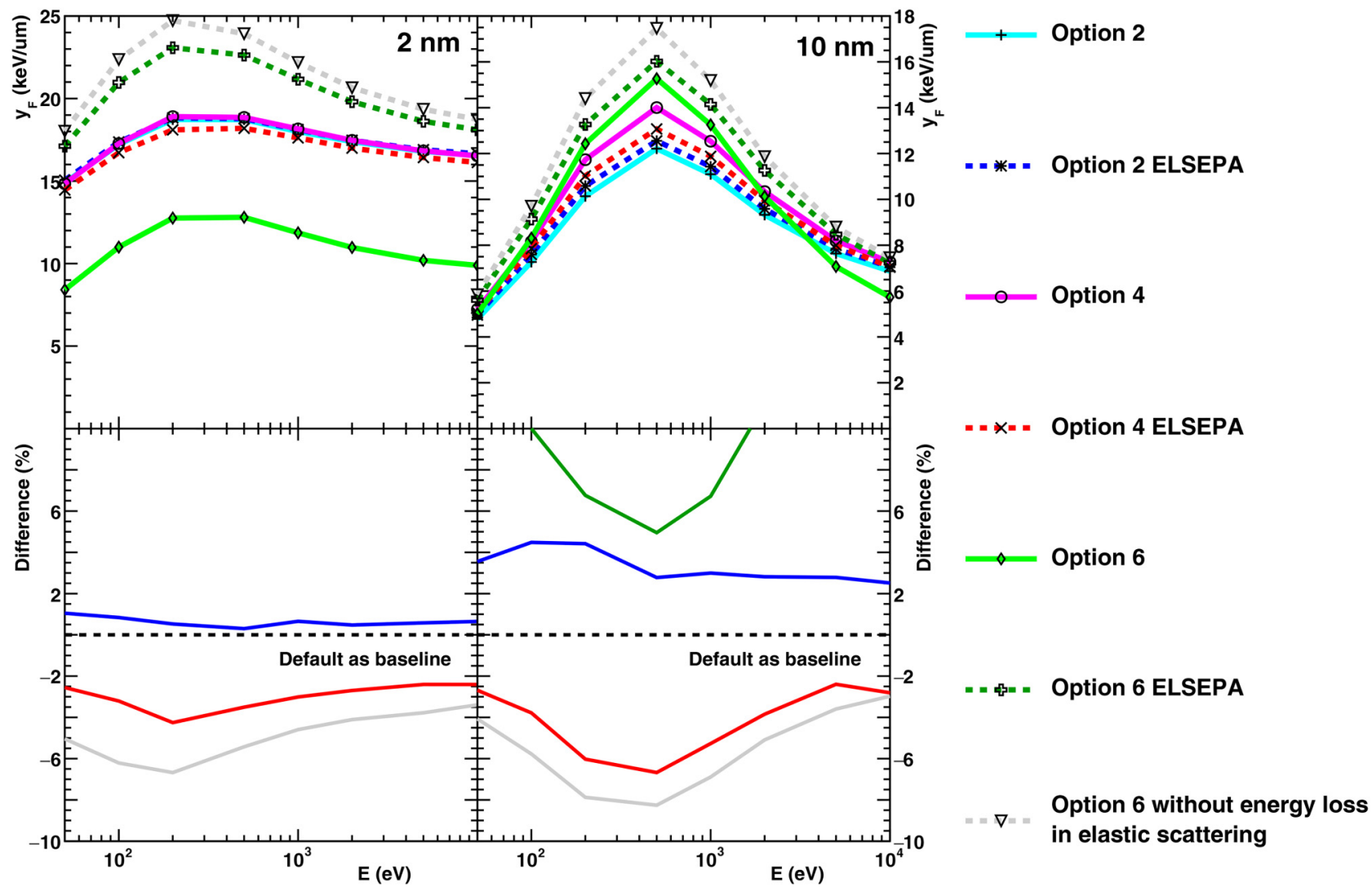

FIG. 10. Frequency-mean lineal energy as a function of incident energy with physics constructors "option 2" (cyan solid), "option 4" (magenta solid), "option 6" (light green solid), "option 6" without energy loss in elastic scatterings (gray dashed) and results of "option 2 ELSEPA" (blue dashed), "option 4 ELSEPA" (red dashed), "option 6 ELSEPA" (green dashed) for a target of diameter $2 \mathrm{~nm}$ (upper left) and $10 \mathrm{~nm}$ (upper right). The bottom figures show the relative differences between "default options" and the "ELSEPA options". The relative differences are with "default options" as reference.

for track structure simulations in liquid water with Geant4-DNA. ${ }^{26}$

In contrast, the SSB yield is less sensitive to the elastic model, with the influence of the ELSEPA- based model being about $1 \%$. Consequently, the ratio between DSB and SSB with the "ELSEPA options" is lower than the ratio obtained with the "default options."

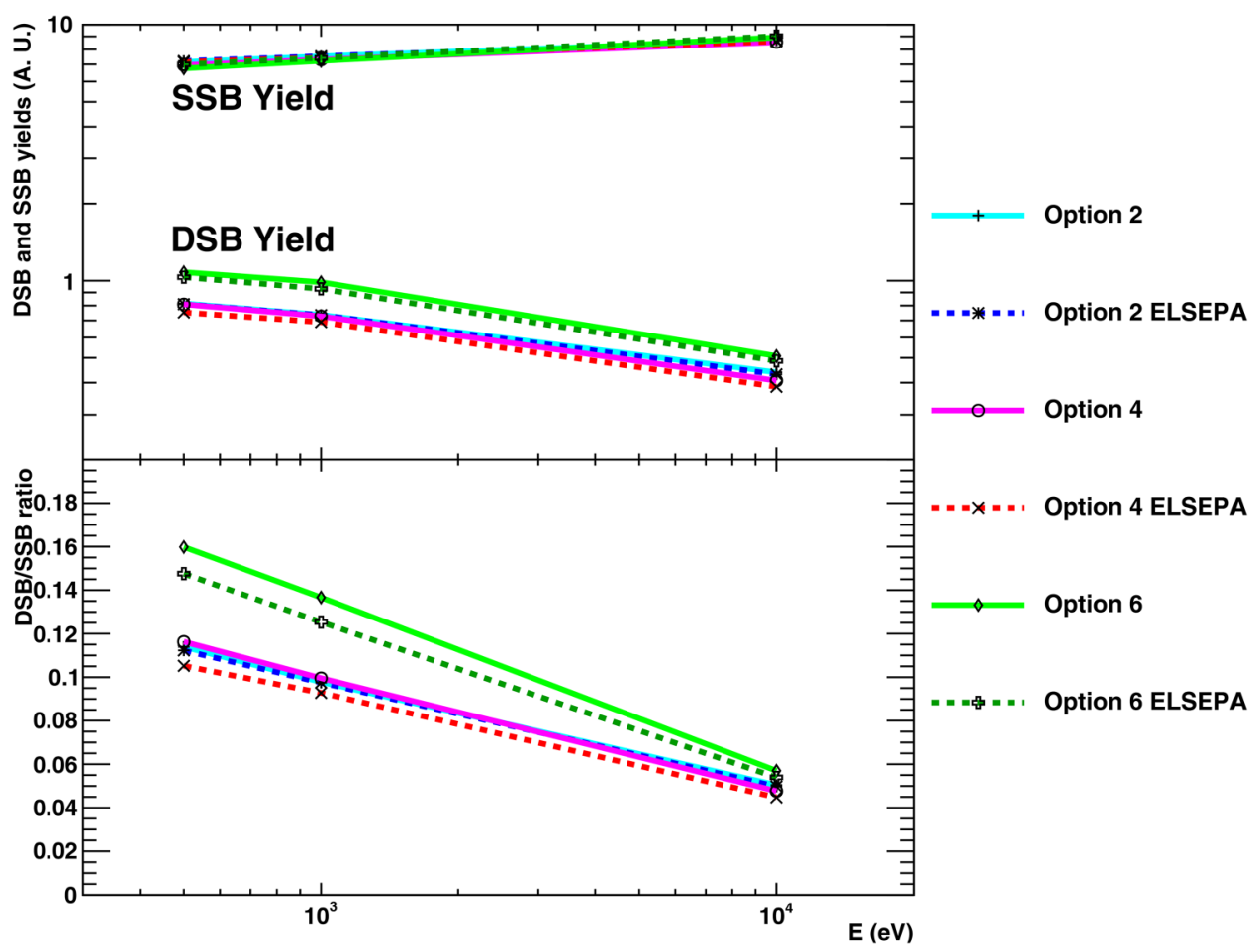

FIG. 11. Yields of DSB and SSB (upper), and DSB/SSB ratio (below) calculated by the clustering algorithm available in Geant4-DNA as a function of incident energy with the physics constructors "option 2" (cyan solid), "option 4" (magenta solid), and "option 6" (light green solid), and the results of "option 2 ELSEPA" (blue dashed), "option 4 ELSEPA" (red dashed), and "option 6 ELSEPA" (green dashed). 


\section{CONCLUSIONS}

We studied a new electron elastic cross section model using the ELSEPA software with the "F-DF-MF-LDA" potential within the Muffin-tin approximation.

The optical parameters entering the above elastic model, including correlation-polarization potential and inelastic absorption potential, have been qualitatively optimized for liquid water as the target medium. Specifically, we used the correlation-polarization potential of LDA with a $1.457 \AA^{3}$ static polarizability, the Buckingham potential for the longtrajectory model, and we suggested an energy dependence for $b_{p o l}$. The inelastic absorption potential has been considered with an absorption strength of 2.5 above $100 \mathrm{eV}$, while linearly varying for energies below $100 \mathrm{eV}$.

The results show improvement compared to the existing Geant4-DNA models such as the SR, USR, and Champion models and compared to experimental data. However, there are still limitations in the present model such as overestimations at a small scattering angle above $500 \mathrm{eV}$ and distortions below $20 \mathrm{eV}$.

We studied the impact of this elastic scattering model using the recommended Geant4-DNA physics constructors ("option 2," "option 4," and "option 6") and TS simulation applications ("range," "TestEm12," "microyz," and "clustering") available in Geant4-DNA. The results of "default options" constructors were compared with the results of the "ELSEPA options" including the new ELSEPA-based elastic model.

Specifically, the range simulations show a similar tendency in comparison with the other approaches described by previous studies. The new elastic model influences the range values up to $20 \%$ mainly at energies below $100 \mathrm{eV}$ due to the dominant contribution of elastic scattering.

Regarding DPKs, the "option 6 ELSEPA" is more diffusive than "option 6" due to the concomitant influence of the number of elastic scatterings and scattering angle values. In the case of "option 4 ELSEPA," the DPKs are more diffusive than "option 4" due to the small scattering angles of ELSEPA-based elastic model. In the case of "option 2," the spread of dose distribution is related to the MTCS of the elastic scattering model, including an energy shift caused by the energy losses due to inelastic interactions. The elastic scattering model with smaller MTCS, representing less elastic scattering and smaller scattering angles, leads to more diffusive dose distribution.

For microdosimetry distributions, the frequency mean lineal energy is more influenced by the energy loss in elastic scattering than by the elastic scattering model. The results of "option 2" were not influenced, and those of "option 4 ELSEPA" and "option 6 ELSEPA" show smaller values by about $5 \%$ in the entire energy.

The clustering example reveals that the effect of the elastic scattering model is negligible for the calculation of SSBs; however, the physics options causing less spread DPK make more DSBs resulting from more concentrated deposited energy. The effect of the new elastic model on the DSB yield is up to $1.3 \%, 7.1 \%$, and $5.8 \%$ for "option 2," "option 4 ," and "option 6 ," respectively.

The reader should keep in mind that the contribution of inelastic processes to penetration values is dominant (e.g., corrections to inelastic scattering cross sections lead to $15 \%-45 \%$ differences ${ }^{12}$ ) compared to the influence of elastic models. Nevertheless, elastic scattering determines the electron spatial distribution and consequently influences radiolysis modeling, required for the simulation of non-direct damage.

Overall, the simulations with the new elastic model show reasonably good agreement with the "default options" for all physics constructors ("option 2," "option 4," and "option 6") and bring improved compatibility with the experimental data. The developed elastic scattering model will soon be incorporated as the new default elastic scattering model in Geant4-DNA for electron transport in liquid water.

\section{ACKNOWLEDGMENTS}

The authors deeply thank Professor Francesc Salvat from the Barcelona University for his helpful advice and for very kindly providing us the ELSEPA code. The authors also thank the University of Bordeaux Initiative of Excellence International Doctorates program in the framework of the "France-Korea Particle Physics Laboratory" International Associated Laboratory (2017-2020). I. Kyriakou and D. Emfietzoglou acknowledge financial support from the European Space Agent (ESA) (Contract No. 4000112863/14/NL/HB).

${ }^{1}$ S. Uehara, H. Nikjoo, and D. T. Goodhead, Radiat. Res. 152, 202 (1999).

${ }^{2}$ W. E. Wilson, J. H. Miller, D. J. Lynch, R. R. Lewis, and M. Batdorf, Radiat. Res. 161, 591 (2004).

${ }^{3}$ H. Nikjoo, S. Uehara, D. Emfietzoglou, and F. A. Cucinotta, Radiat. Meas. 41, 1052 (2006).

${ }^{4}$ S. Incerti, G. Baldacchino, M. Bernal, R. Capra, C. Champion, Z. Francis, P. Guèye, A. Mantero, B. Mascialino, and P. Moretto, Int. J. Model. Simul. Sci. Comput. 1, 157 (2010).

${ }^{5}$ C. Tung, T. Chao, H. Hsieh, and W. Chan, Nucl. Instrum. Meth. B 262, 231 (2007).

${ }^{6} \mathrm{~V}$. Semenenko, J. Turner, and T. Borak, Radiat. Environ. Biophys. 42, 213 (2003).

${ }^{7}$ W. Friedland, M. Dingfelder, P. Kundrat, and P. Jacob, Mutat. Res. 711, 28 (2011).

${ }^{8}$ D. Alloni, A. Campa, W. Friedland, L. Mariotti, and A. Ottolenghi, Int. J. Radiat. Biol. 88, 77 (2012).

${ }^{9}$ H. Nikjoo, D. T. Goodhead, and M. Terrissol, Int. J. Radiat. Biol. 71, 467 (1997).

${ }^{10}$ D. Emfietzoglou, I. Kyriakou, I. Abril, R. Garcia-Molina, and H. Nikjoo, Int. J. Radiat. Biol. 88, 22 (2012).

${ }^{11}$ M. Dingfelder, Appl. Radiat. Isotopes 83, 142 (2014).

${ }^{12}$ D. Emfietzoglou, I. Kyriakou, R. Garcia-Molina, and I. Abril, Surf. Interface Anal. 49, 4 (2017).

${ }^{13}$ M. Dingfelder, D. Hantke, M. Inokuti, and H. G. Paretzke, Radiat. Phys. Chem. 53, 1 (1999).

${ }^{14}$ C. Champion, S. Incerti, H. Aouchiche, and D. Oubaziz, Radiat. Phys. Chem. 78, 745 (2009).

${ }^{15}$ M. C. Bordage, J. Bordes, S. Edel, M. Terrissol, X. Franceries, M. Bardies, N. Lampe, and S. Incerti, Phys. Med. 32, 1833 (2016).

${ }^{16}$ D. Emfietzoglou, F. A. Cucinotta, and H. Nikjoo, Radiat. Res. 164, 202 (2005).

${ }^{17}$ R. Garcia-Molina, I. Abril, I. Kyriakou, and D. Emfietzoglou, Surf. Interface Anal. 49, 11 (2017).

${ }^{18}$ D. Emfietzoglou, Radiat. Phys. Chem. 66, 373 (2003).

${ }^{19}$ H. Nikjoo, D. Emfietzoglou, T. Liamsuwan, R. Taleei, D. Liljequist, and S. Uehara, Rep. Prog. Phys. 79, 116601 (2016).

${ }^{20}$ J. M. Fernández-Varea, X. Llovet, and F. Salvat, Surf. Interface Anal. 37, 824 (2005)

${ }^{21}$ N. F. Mott and H. S. W. Massey, The Theory of Atomic Collisions (Clarendon Press, Oxford, 1965), Vol. 35.

${ }^{22}$ F. Salvat and R. Mayol, Comput. Phys. Commun. 74, 358 (1993).

${ }^{23}$ Atomic and Molecular Data for Radiotherapy and Radiation Research, IAEA-TECDOC-799 (International Atomic Energy Agency, Vienna, 
1995), 756 pp., see https://www-pub.iaea.org/books/IAEABooks/5444/ Atomic-and-Molecular-Data-for-Radiotherapy-and-Radiation-Research.

${ }^{24}$ S. Incerti, I. Kyriakou, M. Bernal, M. C. Bordage, Z. Francis, S. Guatelli, V. Ivanchenko, M. Karamitros, N. Lampe, S. B. Lee, S. Meylan, C. H. Min, W. G. Shin, P. Nieminen, D. Sakata, N. Tang, C. Villagrasa, H. N. Tran, and J. M. C. Brown, Med. Phys. 45, e722 (2018).

${ }^{25} \mathrm{H}$. Aouchiche, C. Champion, and D. Oubaziz, Radiat. Phys. Chem. 77, 107 (2008).

${ }^{26}$ M. Bernal, M. Bordage, J. Brown, M. Davídková, E. Delage, Z. El Bitar, S. Enger, Z. Francis, S. Guatelli, and V. Ivanchenko, Phys. Med. 31, 861 (2015).

${ }^{27}$ S. Incerti, A. Ivanchenko, M. Karamitros, A. Mantero, P. Moretto, H. Tran, B. Mascialino, C. Champion, V. Ivanchenko, and M. Bernal, Med. Phys. 37, 4692 (2010).

${ }^{28}$ F. Salvat, A. Jablonski, and C. J. Powell, Comput. Phys. Commun. 165, 157 (2005).

${ }^{29}$ D. Bote, F. Salvat, A. Jablonski, and C. J. Powell, J. Electron Spectrosc. 175, 41 (2009)

${ }^{30}$ Z. Czyżewski, D. O. N. MacCallum, A. Romig, and D. C. Joy, J. Appl. Phys. 68, 3066 (1990).

${ }^{31}$ A. Wambersie, M. Inokuti, and S. M. Seltzer, J. Internat. Commission Radiat. Units Meas. 7(1), 1 (2007).

${ }^{32}$ A. Zecca, R. Melissa, R. S. Brusa, and G. P. Karwasz, Phys. Lett. A 257, 75 (1999).

${ }^{33}$ E. Zeitler and H. Olsen, Phys. Rev. 162, 1439 (1967).

${ }^{34}$ F. Salvat, Phys. Rev. A 68, 012708 (2003).

${ }^{35}$ A. C. Yates, Phys. Rev. 176, 173 (1968).

${ }^{36}$ D. Liljequist, T. Liamsuwan, and H. Nikjoo, Int. J. Radiat. Biol. 88, 29 (2012)

${ }^{37}$ P. L. Silvestrelli and M. Parrinello, J. Chem. Phys. 111, 3572 (1999).

${ }^{38}$ B. Abel, U. Buck, A. L. Sobolewski, and W. Domcke, Phys. Chem. Chem. Phys. 14, 22 (2012).

${ }^{39}$ R. A. Buckingham, Proc. R. Soc. A 168, 264 (1938).

${ }^{40}$ J. Lindhard and A. Winther, Nucl. Phys. A 166, 413 (1971).

${ }^{41}$ D. Emfietzoglou and M. Moscovitch, Nucl. Instrum. Meth. B 193, 71 (2002).

${ }^{42}$ M. Terrissol and A. Beaudre, Radiat. Prot. Dosim. 31, 175 (1990).

${ }^{43}$ B. Grosswendt and E. Waibel, Nucl. Instrum. Methods 155, 145 (1978).

${ }^{44}$ S. Uehara, H. Nikjoo, and D. T. Goodhead, Phys. Med. Biol. 37, 1841 (1992).

${ }^{45}$ W. Hilgner and J. Kessler, Z. Phys. A Hadron. Nucl. 221, 305 (1969).

${ }^{46}$ A. Danjo and H. Nishimura, J. Phys. Soc. Jpn. 54, 1224 (1985).

${ }^{47}$ A. Katase, K. Ishibashi, Y. Matsumoto, T. Sakae, S. Maezono, E. Murakami, K. Watanabe, and H. Maki, J. Phys. B At. Mol. Opt. 19, 2715 (1986).

${ }^{48}$ O. Sueoka, S. Mori, and Y. Katayama, J. Phys. B At. Mol. Opt. 19, L373 (1986).

${ }^{49}$ T. W. Shyn and S. Y. Cho, Phys. Rev. A Gen. Phys. 36, 5138 (1987).

${ }^{50}$ Z. Saglam and N. Aktekin, J. Phys. B At. Mol. Opt. 24, 3491 (1991).

${ }^{51}$ W. M. Johnstone and W. R. Newell, J. Phys. B At. Mol. Opt. 24, 3633 (1991).

${ }^{52}$ T. W. Shyn and A. Grafe, Phys. Rev. A 46, 4406 (1992).

${ }^{53}$ H. Cho, Y. S. Park, H. Tanaka, and S. J. Buckman, J. Phys. B At. Mol. Opt. 37, 625 (2004).

${ }^{54}$ M. A. Khakoo, H. Silva, J. Muse, M. C. A. Lopes, C. Winstead, and V. McKoy, Phys. Rev. A 87, 049902 (2013).

${ }^{55}$ M. Michaud, A. Wen, and L. Sanche, Radiat. Res. 159, 3 (2003).

${ }^{56}$ Z. Francis, S. Incerti, R. Capra, B. Mascialino, G. Montarou, V. Stepan, and C. Villagrasa, Appl. Radiat. Isotopes 69, 220 (2011).

${ }^{57}$ V. Ivanchenko, S. Incerti, Z. Francis, H. Tran, M. Karamitros, M. Bernal, C. Champion, and P. Gueye, Nucl. Instrum. Meth. B 273, 95 (2012).

${ }^{58}$ Z. Francis, S. Incerti, M. Karamitros, H. N. Tran, and C. Villagrasa, Nucl. Instrum. Meth. B 269, 2307 (2011).

${ }^{59}$ H. Tran, Z. El Bitar, C. Champion, M. Karamitros, M. Bernal, Z. Francis, V. Ivantchenko, S. Lee, J. Shin, and S. Incerti, Nucl. Instrum. Meth. B 343, 132 (2015).

${ }^{60} \mathrm{C}$. Champion, S. Incerti, Y. Perrot, R. Delorme, M. C. Bordage, M. Bardies, B. Mascialino, H. N. Tran, V. Ivanchenko, M. Bernal, Z. Francis, J. E. Groetz, M. Fromm, and L. Campos, Appl. Radiat. Isotopes 83(Pt B), 137 (2014).

${ }^{61}$ J. Bordes, S. Incerti, N. Lampe, M. Bardiès, and M.-C. Bordage, Nucl. Instrum. Meth. B 398, 13 (2017).

${ }^{62}$ Z. Francis, C. Villagrasa, and I. Clairand, Comput. Meth. Prog. Biol. 101, 265 (2011).
${ }^{63}$ Z. Francis, S. Incerti, V. Ivanchenko, C. Champion, M. Karamitros, M. A. Bernal, and Z. El Bitar, Phys. Med. Biol. 57, 209 (2012).

${ }^{64}$ L. Pages, E. Bertel, H. Joffre, and L. Sklavenitis, Atom. Data Nucl. Data 4, 1 (1972).

${ }^{65}$ F. Rohrlich and B. C. Carlson, Phys. Rev. 93, 38 (1954).

${ }^{66}$ R. M. Sternheimer, Phys. Rev. 145, 247 (1966).

${ }^{67}$ H. W. Koch and J. W. Motz, Rev. Mod. Phys. 31, 920 (1959).

${ }^{68}$ D. E. Watt, Quantities For Generalized Dosimetry of Ionizing Radiations in Liquid Water (CRC Press, 1996).

${ }^{69}$ M. J. Berger, M. Inokuti, H. H. Anderson, H. Bichsel, J. A. Dennis, D. Powers, S. M. Seltzer, and J. E. Turner, J. Int. Comm. Radiat. Units Meas. os19(2), NP (1984).

${ }^{70}$ J. Ashley, J. Electron Spectrosc. 46, 199 (1988).

${ }^{71} \mathrm{~J}$. Ziegler, Handbook of Stopping Cross-Sections for Energetic Ions in All Elements (Pergamon Press, Elmsford, NY, 1980), Vol. 5.

${ }^{72}$ H. Iskef, J. Cunningham, and D. E. Watt, Phys. Med. Biol. 28, 535 (1983).

${ }^{73}$ A. Akkerman and E. Akkerman, J. Appl. Phys. 86, 5809 (1999).

${ }^{74}$ M. Gryziński, Phys. Rev. 138, A336 (1965).

${ }^{75}$ A. F. Akkerman and G. Y. Chernov, Sov. Phys. Tech. Phys. 23, 247 (1978).

${ }^{76}$ A. Akkerman, A. Gibrekhterman, A. Breskin, and R. Chechik, J. Appl. Phys. 72, 5429 (1992).

${ }^{77}$ J. Meesungnoen, J. P. Jay-Gerin, A. Filali-Mouhim, and S. Mankhetkorn, Radiat. Res. 158, 657 (2002).

${ }^{78}$ V. Cobut, Y. Frongillo, J. P. Patau, T. Goulet, M.-J. Fraser, and J. P. Jay-Gerin, Radiat. Phys. Chem. 51, 229 (1998).

${ }^{79}$ P. Rowntree, L. Parenteau, and L. Sanche, J. Chem. Phys. 94, 8570 (1991).

${ }^{80}$ S. M. Pimblott and L. D. A. Siebbeles, Nucl. Instrum. Meth. B 194, 237 (2002).

${ }^{81}$ S. M. Pimblott, J. A. LaVerne, and A. Mozumder, J. Phys. Chem. B 100, 8595 (1996).

${ }^{82}$ H. G. Paretzke, J. E. Turner, R. N. Hamm, H. A. Wright, and R. H. Ritchie, J. Chem. Phys. 84, 3182 (1986).

${ }^{83}$ S. M. Pimblott, J. A. LaVerne, A. AlbaGarcia, and L. D. Siebbeles, J. Phys. Chem. B 104, 9607 (2000).

${ }^{84}$ J. Fernández-Varea, D. Liljequist, S. Csillag, R. Räty, and F. Salvat, Nucl. Instrum. Meth. B 108, 35 (1996).

${ }^{85}$ F. Salvat, Radiat. Phys. Chem. 53, 247 (1998).

${ }^{86}$ D. N. Nikogosyan, A. A. Oraevsky, and V. I. Rupasov, Chem. Phys. 77, 131 (1983)

${ }^{87}$ D. M. Bartels and R. A. Crowell, J. Phys. Chem. A 104, 3349 (2000).

${ }^{88}$ W. E. Wilson and H. Nikjoo, Radiat. Environ. Biophys. 38, 97 (1999).

${ }^{89}$ A. Jablonski, F. Salvat, and C. J. Powell, NIST Stand. Ref. Database 64 (2010).

${ }^{90}$ S. Uehara and H. Nikjoo, Radiat. Res. 47, 69 (2006).

${ }^{91}$ I. Plante and F. A. Cucinotta, N. J. Phys. 11, 063047 (2009).

${ }^{92}$ M. Rudd, Radiat. Prot. Dosim. 31, 17 (1990).

${ }^{93}$ S. M. Seltzer and M. J. Berger, Atom. Data Nucl. Data 35, 345 (1986).

${ }^{94}$ I. Kaplan and V. Y. Sukhonosov, Radiat. Res. 127, 1 (1991).

${ }^{95}$ G. Kutcher and A. Green, Radiat. Res. 67, 408 (1976).

${ }^{96}$ D. J. Brenner and M. Zaider, Phys. Med. Biol. 29, 443 (1983).

${ }^{97}$ K. Wiklund, J. M. Fernandez-Varea, and B. K. Lind, Phys. Med. Biol. 56, 1985 (2011).

${ }^{98}$ S. M. Seltzer, J. M. Fernández-Varea, P. Andreo, P. M. Bergstrom., Jr., D. T. Burns, I. K. Bronié, C. K. Ross, and F. Salvat, "Key data for ionizing-radiation dosimetry: Measurement standards and applications," ICRU Report 90, 2014

${ }^{99}$ M. J. Berger, J. Coursey, M. Zucker, and J. Chang, Stopping-Power and Range Tables for Electrons, Protons, and Helium Ions (NIST Physics Laboratory, Gaithersburg, MD, 1998).

${ }^{100}$ D. Emfietzoglou, G. Papamichael, and H. Nikjoo, Radiat. Res. 188, 355 (2017).

${ }^{101}$ D. Emfietzoglou, K. Karava, G. Papamichael, and M. Moscovitch, Phys. Med. Biol. 48, 2355 (2003)

${ }^{102}$ B. Bransden, M. McDowell, C. Noble, and T. Scott, J. Phys. B At. Mol. Opt. 9, 1301 (1976).

${ }^{103}$ L. Maigne, Y. Perrot, D. R. Schaart, D. Donnarieix, and V. Breton, Phys. Med. Biol. 56, 811 (2011)

${ }^{104}$ Z. Nikitaki, V. Nikolov, I. V. Mavragani, E. Mladenov, A. Mangelis, D. A. Laskaratou, G. I. Fragkoulis, C. E. Hellweg, O. A. Martin, and D. Emfietzoglou, Free Radic. Res. 50, S64 (2016).

${ }^{105}$ N. Lampe, M. Karamitros, V. Breton, J. M. Brown, I. Kyriakou, D. Sakata, D. Sarramia, and S. Incerti, Phys. Med. 48, 135 (2018). 